\title{
A Dlx2- and Pax6-Dependent Transcriptional Code for Periglomerular Neuron Specification in the Adult Olfactory Bulb
}

\author{
Monika S. Brill, ${ }^{1,2,3}$ Marina Snapyan, ${ }^{4}$ Hilde Wohlfrom, ${ }^{1,2,3}$ Jovica Ninkovic, ${ }^{2,3}$ Melanie Jawerka, ${ }^{1,2,3}$ Grant S. Mastick, ${ }^{5}$ \\ Ruth Ashery-Padan, ${ }^{6}$ Armen Saghatelyan, ${ }^{4}$ Benedikt Berninger, ${ }^{1,2,3}$ and Magdalena Götz ${ }^{1,2,3}$ \\ ${ }^{1}$ Department of Physiological Genomics, Institute of Physiology, Ludwig-Maximilians University Munich, D-80336 Munich, Germany, ${ }^{2}$ Institute for Stem \\ Cell Research, Helmholtz Zentrum München, German Research Center for Environmental Health, D-85764 Neuherberg, Germany, ${ }^{3}$ Munich Center for \\ Integrated Protein Science, 81377 Munich, Germany, ${ }^{4}$ Unité de Neurobiologie Cellulaire, Centre de Recherche Université Laval Robert-Giffard, Québec, \\ Québec, Canada G1J 2G3, ${ }^{5}$ Biology Department, University of Nevada, Reno, Reno, Nevada 89557, and ${ }^{\circ}$ Department of Human Molecular Genetics and \\ Biochemistry, Sackler Faculty of Medicine, Tel Aviv University, Ramat Aviv 69978, Tel Aviv, Israel
}

Distinct olfactory bulb $(\mathrm{OB})$ interneurons are thought to become specified depending on from which of the different subregions lining the lateral ventricle wall they originate, but the role of region-specific transcription factors (TFs) in the generation of OB interneurons diversity is still poorly understood. Despite the crucial roles of the Dlx family of TFs for patterning and neurogenesis in the ventral telencephalon during embryonic development, their role in adult neurogenesis has not yet been addressed. Here we show that in the adult brain, Dlx 1 and Dlx2 are expressed in progenitors of the lateral but not the dorsal subependymal zone (SEZ), thus exhibiting a striking regional specificity. Using retroviral vectors to examine the function of Dlx2 in a cell-autonomous manner, we demonstrate that this TF is necessary for neurogenesis of virtually all $\mathrm{OB}$ interneurons arising from the lateral SEZ. Beyond its function in generic neurogenesis, Dlx2 also plays a crucial role in neuronal subtype specification in the $0 B$, promoting specification of adult-born periglomerular neurons (PGNs) toward a dopaminergic fate. Strikingly, Dlx2 requires interaction with Pax6, because Pax6 deletion blocks Dlx2-mediated PGN specification. Thus, Dlx2 wields a dual function by first instructing generic neurogenesis from adult precursors and subsequently specifying PGN subtypes in conjunction with Pax6.

Key words: neurogenesis; subependymal zone; olfactory bulb; transcription factor; tyrosine hydroxylase; stem cell

\section{Introduction}

Two regions in the adult mammalian forebrain receive a constant supply of new neurons, the olfactory bulb (OB) and the dentate gyrus (Ming and Song, 2005). Whereas adult-born dentate granule neurons originate from local radial glia-like cells (for review, see Ming and Song, 2005), the origin of OB interneurons is more complex, because they are generated at some distance and in diverse regions. Although the lateral wall of the lateral ventricle [the lateral subependymal zone (SEZ)] appears to be the major source of adult $\mathrm{OB}$ neurogenesis,

\footnotetext{
Received Feb. 15, 2008; revised April 17, 2008; accepted May 7, 2008.

This work was supported by grants from the Deutsche Forschungsgemeinschaft to the excellence cluster Center for Integrated Protein Science; the European Union; Bundesministerium für Bildung und Forschung (M.G.); the Bavarian State Ministry of the Sciences, Research, and the Arts (M.G., B.B.); National Institutes of Health Grants HD38069 and NS054740 and March of Dimes \#1-FY06-387 (G.S.M.); and Canadian Institutes of Health Research grants (A.S.). We are very grateful to Dr. Jhumku D. Kohtz for the Dlx antibody and to Dr. Robert Blum for primer design. We thank Dr. Kenny Campbell for insightful comments on this manuscript and Dr. Dorothea Schulte for providing the purified and concentrated monoclonal Pax6 antibody obtained from the supernatant of cells from the Developmental Studies Hybridoma Bank. We also thank Susanne Schickle, Petra Peters, Gabriele Jäger, and Tatiana Simon-Ebert for excellent technical assistance.

Correspondence should be addressed to Magdalena Götz at the above addresses. E-mail: magdalena.goetz@helmholtz-muenchen.de.

D0I:10.1523/JNEUROSCI.0700-08.2008

Copyright $\odot 2008$ Society for Neuroscience $\quad$ 0270-6474/08/286439-14\$15.00/0
}

injections of permanent lineage tracers into the lateral SEZ hardly labeled any progeny migrating to the glomerular layer (GL) of the $\mathrm{OB}$, whereas more such cells were observed after injection into the rostral migratory stream (RMS) (Hack et al., 2005; Mendoza-Torreblanca et al., 2008). Different regions of origin for distinct types of periglomerular neurons (PGNs) were recently further substantiated by transplantation experiments (De Marchis et al., 2007; Kohwi et al., 2007; Merkle et al., 2007) and Cre-mediated fate mapping (WillaimeMorawek et al., 2006; Kohwi et al., 2007; Ventura and Goldman, 2007; Young et al., 2007). Because adult neurogenesis originates from stem or progenitor cells not only in the lateral, but also medial and dorsal SEZ, this raises the question whether distinct molecular determinants mediating patterning at earlier developmental stages may still be active in the adult and influence the subtype specification of $\mathrm{OB}$ interneurons.

During development, the vast majority of telencephalic interneurons originate in the ventral part of the telencephalon (Wilson and Rubenstein, 2000; Corbin et al., 2001; Marin and Rubenstein, 2001; Anderson et al., 2002), whereas glutamatergic neurons arise from the dorsal telencephalon (Gorski et al., 2002; Malatesta et al., 2003; Kroll and O'Leary, 2005). Interneuron de- 
velopment depends on the transcription factors (TFs) Gsh1, Gsh2, Dlx1, and Dlx2, which are all expressed in the ventral telencephalon (Anderson et al., 1997; Eisenstat et al., 1999; Toresson et al., 2000; Toresson and Campbell, 2001), whereas Pax6 governs the generation of glutamatergic neurons (Stoykova et al., 1996; Heins et al., 2002; Kroll and O'Leary, 2005; Nikoletopoulou et al., 2007). In adult neurogenesis, however, Pax6 plays a role for GABA and dopaminergic neuron specification (Hack et al., 2005; Kohwi et al., 2005), with the TF Sp8 being required for development of a distinct subset of the PGNs, the calretinin-positive (calretinin +) cells (Waclaw et al., 2006). Thus, distinct subsets of interneurons may originate from different sets of progenitors that are specified by TFs depending on their respective region of origin.

The key molecular regulators for GABAergic neuron specification during development are Gsh1, Gsh2, Dlx1, and Dlx2, as indicated by the fact that the respective double mutant mice lose virtually all GABAergic telencephalic interneurons before birth (Anderson et al., 1997; Eisenstat et al., 1999; Toresson et al., 2000; Toresson and Campbell, 2001). However, the function of these TFs in adult neurogenesis is yet unknown, because most of the mouse mutants die perinatally. We therefore aimed to determine here whether Dlx TFs maintain their region-specific expression in the adult forebrain and whether they still act to determine all or only a specific subset of $\mathrm{OB}$ interneurons.

\section{Materials and Methods}

\section{Animals and stereotactic injections}

Eight- to 10-week-old C57BL/6J mice or mice containing the Pax6 gene flanked by loxP sites (Ashery-Padan et al., 2000) were used in this study. All animal procedures were performed in accordance to the Policies on the Use of Animals and Humans in Neuroscience Research, revised and approved by the Society of Neuroscience and the state of Bavaria under license number 55.2-1-54-2531-23/04. For retroviral injections, mice were deeply anesthetized [ketamine $(100 \mathrm{mg} / \mathrm{kg}$; CP-Pharma) and xylazine (5 mg/kg; Rompun; Bayer)] and injected with $0.5-1 \mu \mathrm{l}$ of viral suspension at the following coordinates (relative to bregma): for SEZ, 0.7 (anteroposterior), 1.2 (mediolateral), and 2.0-1.6 (dorsoventral); and for RMS, 2.55 (anteroposterior), 0.8 (mediolateral), and 3.2-3.0 (dorsoventral).

\section{Retroviral plasmid construction and virus preparation}

The Dlx2 complete cDNA (Andrews et al., 2003) was inserted in sense orientation into the EcoRI and XhoI site of the retroviral vector pMXIG (Nosaka et al., 1999; Hack et al., 2005; Colak et al., 2008) between the upstream LTR and the IRES sequence. The Dlx2-Engrailed fusionconstruct was made by subcloning the homeodomain-coding region of mouse Dlx2 (pCAX-Dlx2) and the Engrailed repressor domain (pSlax13EnR; kindly provided by M. Kengaku, RIKEN Brain Science Institute, Saitama, Japan) by PCR. The amplified fragments were then digested with XhoI and XbaI (for Dlx2 homeodomain) and with BamHI and XhoI (for Engrailed repressor domain) and ligated into pCDNA 3.1. The fusion protein was digested with $\mathrm{BamHI}$ and $\mathrm{XbaI}$ and inserted into the retroviral vector pMXIG. Viral plasmids were transfected into gpg helperfree packaging cells to generate VSV-G (vesicular stomatitis virus glycoprotein)-pseudotyped viral particles (Pear et al., 1993; Yee et al., 1994; Hack et al., 2004; Colak et al., 2008), which were used for injections when titers were $>10^{6}$ viral particles $/ \mu$ l.

\section{Cell culture experiments}

Adult neurosphere cultures. For culturing neurosphere cells from adult subependyma, we followed the protocol described by Johansson et al. (1999). Cells isolated from the lateral wall of the lateral ventricle were cultured in the presence of $20 \mathrm{ng} / \mathrm{ml}$ EGF and $10 \mathrm{ng} / \mathrm{ml} \mathrm{FGF} 2$ under nonadherent conditions to allow for the formation of neurospheres. Neurosphere cells were passaged three times and then plated dissociated on poly-D-lysine coated coverslips at a density of 120,000 cells per well (24-well plates) in medium containing EGF and FGF2. At that stage, cells were transduced with pseudotyped retroviruses as described by Hack et al. (2004). The next day, the medium was replaced by Neurobasal supplemented with B27.

Primary SEZ cultures. For primary subependymal cultures, six mice were prepared, and the cells were directly plated after preparation on six coverslips coated with poly-D-lysine without any addition of EGF and FGF2 in DMEM/F12-supplemented medium and were transduced $2 \mathrm{~h}$ later. After $7 \mathrm{~d}$ in culture, cells were fixed with $4 \%$ paraformaldehyde (PFA) in PBS for $15 \mathrm{~min}$ at room temperature and processed for antibody staining.

Primary embryonic cerebral cortex cultures. Embryos were isolated from timed pregnant mice at embryonic day 13 (E13; the day of the vaginal plug was considered embryonic day 0 ), and the telencephalons were dissected. In HBSS containing $10 \mathrm{~mm}$ HEPES, first the telencephalic hemispheres were separated, then the hippocampal region and the ganglionic eminences as well as the meninges were removed, and the isolated cortical hemispheres were then briefly centrifuged to remove the HBSS/ HEPES; 2-3 ml of DMEM-Glutamax (Invitrogen) containing 10\% FCS and penicillin/streptomycin (100 U/ml penicillin and $100 \mathrm{mg} / \mathrm{ml}$ streptomycin; Sigma) was added, and cells were dissociated mechanically using a fire-polished Pasteur pipette. The homogeneous cell suspension was counted using a Neubauer chamber and plated at a density of $3 \times 10^{5}$ cells/well in a 24-well plate on coverslips coated with poly-D-lysine in 500 $\mu \mathrm{l}$ of medium. Retroviral transduction was performed $2 \mathrm{~h}$ after plating, and after $1 \mathrm{~d}$ in vitro, $500 \mu \mathrm{l}$ of medium DMEM-Glutamax containing penicillin/streptomycin and supplemented with B27 (Invitrogen) was added to reduce the serum concentration to $5 \%$. After $6 \mathrm{~d}$ in vitro, cells were fixed and processed as described above.

\section{Histological procedures and BrdU labeling}

For immunohistochemistry, animals were deeply anesthetized using 5\% chloral hydrate $(0.15 \mathrm{ml} / 10 \mathrm{~g}$ of body weight $)$ and transcardially perfused first with PBS, followed by $4 \%$ PFA in PBS. Brains were cryoprotected and cut, and immunostainings were performed on $20 \mu \mathrm{m}$ sections; alternatively, vibratome sections were cut at $60 \mu \mathrm{m}$ thickness. 5-Bromo-2'deoxyuridine (BrdU) was stained after $2 \mathrm{M} \mathrm{HCl}$ pretreatment for $45 \mathrm{~min}$ followed by incubation in borate buffer $(0.1 \mathrm{M}, 10 \mathrm{~min})$ for neutralization of the $\mathrm{pH}$. The following primary antibodies were used in this study: $\alpha$-green fluorescent protein (GFP; rabbit, 1:500, Invitrogen, A6455 or chick, Aves Labs, GFP-1020); $\alpha$-pan-Dlx (rabbit, 1:750, kind gift from J. Kohtz, Children's Memorial Hospital and Feinberg School of Medicine, Northwestern University, Chicago, IL); $\alpha$-Dlx2 (rabbit, 1:500, Millipore Bioscience Research Reagents, AB5726); $\alpha$-doublecortin (DCX; guinea pig, 1:2000, Millipore Bioscience Research Reagents, AB5910 or rabbit, 1:2000, Abcam, ab18723); $\alpha$-NeuN (mouse, 1:100, Millipore Bioscience Research Reagents, MAB377); $\alpha$-BrdU (rat, 1:400, Abcam, ab 38890); $\alpha$-GFAP (mouse, 1:500, Sigma, G 9269); $\alpha$-Olig2 (rabbit, 1:1000, Millipore Bioscience Research Reagents, AB9610); $\alpha$-Mash1 (mouse, 1:200, kindly provided by D. Anderson, California Institute of Technology, Pasadena, CA); $\alpha$-adenomatous polyposis coli protein (APC; mouse, 1:100, EMD Biosciences, OP80); $\alpha$-NG2 (rabbit, 1:200, Millipore Bioscience Research Reagents, AB5320); $\alpha$ - $\beta$-tubulin isotype III ( $\alpha$-TuJ1; mouse, 1:500, Sigma, T 8660); $\alpha$-calretinin (mouse, 1:2000, BD Biosciences, 610908); $\alpha$-tyrosine hydroxylase (TH) (mouse, 1:500, Millipore Bioscience Research Reagents, MAB5280); $\alpha$-Pax6 (mouse, 1:3000, Developmental Studies Hybridoma Bank); $\alpha$-calbindin (mouse, 1:1000, Sigma, C 9848); and $\alpha$-RFP (rabbit, 1:500, Millipore Bioscience Research Reagents, AB3216).

The $\alpha$-GFP antibody was raised against the GFP from the jellyfish Aequorea victoria and is available as complete antiserum. In case of the chick $\alpha$-GFP, chickens were immunized with purified recombinant GFP protein emulsified with Freund's adjuvant. Eggs were collected, and IgY fractions were prepared from the yolks. The $\alpha$-pan-Dlx (Panganiban et al., 1995) was kindly provided by Dr. J. Kohtz. For immunization of rabbits, a 200 aa protein that comprised the homeodomain and $\mathrm{N}$-terminal sequences of the butterfly Dll peptide was used. The $\alpha$-Dlx2 antibody recognizes Dlx2, and immunization was done with a synthetic peptide from human Dlx2 (amino acids 24-39). A synthetic peptide 
corresponding to mouse and human DCX protein was used as immunogen for the $\alpha$-DCX antibody made in guinea pig. The antiserum has been tested on tissue sections from mouse CNS; it works best in the adult forebrain. For the rabbit $\alpha$-DCX antibody, a synthetic peptide conjugated to KLH derived from within residues 300 to the $\mathrm{C}$ terminus of human DCX was used. This antibody detects a specific band of $70 \mathrm{kDa}$ in mouse brain lysates. The $\alpha$-NeuN antibody was raised against purified cell nuclei from mouse brain. It reacts with most neuronal cell types throughout the nervous system of mice. The few cell types not reactive for this antibody include Purkinje, mitral, and photoreceptor cells (Mullen et al., 1992). The $\alpha$-BrdU antibody was raised against the chemical BrdU coupled to KLH in Freund's adjuvant. The $\alpha$-GFAP antibody was raised against purified human GFAP and purified by ion-exchange chromatography. The antibody has been shown to stain astrocytes in purified astrocyte cultures in vitro and by double staining with other markers in mouse brains in vivo (Heins et al., 2002; Buffo et al., 2005). The $\alpha$-Olig2 antibody recognizes a $32 \mathrm{kDa}$ Olig2 protein by Western blot, and recombinant mouse Olig 2 was used as immunogen. The $\alpha$-Mash 1 antibody was kindly provided by Dr. D. Anderson. Mice were immunized with electroeluted, acetone-precipitated pET-MASH1 protein emulsified in complete Freund's adjuvant, and the antibody was tested for specificity in immunocytochemistry in rat embryos (Lo et al., 1991). The $\alpha$-APC antibody was raised against a recombinant $\mathrm{N}$-terminal fragment of APC and is well suited for immunohistochemistry studies of oligodendrocytes because of the antibody's staining of the cell body as opposed to the myelinated processes (McTigue et al., 2001; Ding et al., 2003). Immunoaffinitypurified NG2 chondroitin sulfate proteoglycan from rat was used to make the $\alpha$-NG2 antibody. It recognizes both the intact proteoglycan and the core protein by Western blot and ELISA. Monoclonal $\alpha$-TuJ1 specifically recognizes an epitope located on human $\beta$-tubulin (isotype III). It cross-reacts with bovine and rat in an immunoblotting technique in which it localizes the tubulin band in either a rat brain extract or a bovine brain MAP (microtubule-associated protein) extract. The antibody $\alpha$-calretinin was raised against rat calretinin (amino acids 38-151) and tested in Western blot and immunocytochemistry. Purified tyrosine hydroxylase from a rat pheochromocytoma has been used to produce the $\alpha$-TH antibody. Cell lines such as the PC 12 line, which is derived from a rat pheochromocytoma also, show positive reactions. In immunoblots of adrenal medulla tissue, the antibody recognizes a single protein band of $60 \mathrm{kDa}$. The $\alpha$-Pax6 antibody was self-made from hybridoma cells obtained by the Developmental Studies Hybridoma Bank by Dr. D. Schulte (Max-Planck Institute for Brain Research, Frankfurt, Germany) and purified with a protein A or $\mathrm{G}$ column. As immunogen, a recombinant chick Pax6 protein (amino acids 1-223) was used. As immunogen for the $\alpha$-calbindin antibody, bovine kidney calbindin-D was used. The $\alpha$-calbindin antibody does not react with other members of the EF-hand family, such as calbindin-D-9K, calretinin, myosin light chain, parvalbumin, S-100a, S-100b, S-100A2 (S100L), and S-100A6 (calcyclin). The $\alpha$-RFP antibody was raised against the RFP fusion protein and can be used for immunoblotting and immunocytochemistry.

Omission of the primary antibody resulted in no specific immunolabeling and was used to prove specific labeling of the above used antibodies. Primary antibodies were incubated on specimen overnight at $4^{\circ} \mathrm{C}$ in 0.1 м PBS containing $0.5 \%$ Triton X-100 and $10 \%$ normal goat serum, washed two to three times, and detected by appropriate species- or subclass-specific secondary antibodies conjugated to Alexa 488 (1:1000, Invitrogen), Cy2, Cy3 (1:1000, Dianova), or biotin (1:200, Vector Laboratories). After the secondary antibody incubation, sections were washed again and coverslipped. Some transcription factors were detected by high-sensitivity tyramide signal amplification (Perkin-Elmer) that allowed amplification of the signal and simultaneous detection of two antibodies rose in the same animal.

For detection of proliferating cells, the DNA base analogon BrdU (Sigma) was injected intraperitoneally (50 mg/kg of body weight) $1 \mathrm{~h}$ before perfusion to label fast-proliferating cells (short pulse).

Stainings were analyzed at an Olympus FV1000 laser-scanning confocal microscope with optical sections of maximum 1-2 $\mu \mathrm{m}$ intervals. Virally transduced cells were identified by GFP immunoreactivity, and colocalization with cell type-specific antigens was quantified either in single optical sections of confocal pictures or for each GFP + cell at high magnification with the epifluorescence Olympus microscope (BX61). Between 5 and 10 sections per animal or between 3 and 5 coverslips were counted per experiment until comparable numbers of transduced GFP + cells per animals or experiments were reached.

\section{In situ hybridization}

The following plasmids were used to generate digoxigenin-labeled probes: pCRII-Dlx1 (NotI, Sp6; kindly provided by K. Campbell, Cincinnati Children's Hospital Medical Center, University of Cincinnati College of Medicine, Cincinnati, OH), pBS E61-Dlx2 (EcoRI, T3; kindly provided by Bethan Thomas, King's College London Dental Institute at Guy's, King's College and St. Thomas' Hospitals, London, UK), pSKDlx5 (EcoRI, T7), and pCR2.1-Dlx6 (SpeI, T7; kindly provided by G. Merlo, University of Turin, Turin, Italy). Digoxigenin-labeled RNA probes were generated by in vitro transcription (NTP labeling mix, Roche and T3, T7, or SP6 polymerase, Stratagene) and in situ hybridization was performed on $80 \mu \mathrm{m}$ vibratome sections of perfused brains following standard protocols using a $\alpha$-digoxigenin antibody (Roche, 1:2000).

\section{Coimmunoprecipitation}

Tissue from 8-10 adult C57BL/6J mice containing freshly dissected olfactory bulbs, SEZ, or cerebral cortices were lysed according to standard protocols in the presence of protease inhibitors, and total lysates was prepared. Protein G agarose beads (50\%; Roche) were preincubated with purified monoclonal Pax6 antibody (Developmental Studies Hybridoma Bank), and the different lysates were incubated overnight at $4^{\circ} \mathrm{C}$ with the antibody-coated agarose beads. The following day, agarose beads with immunoprecipitates were washed at least four times (the last washing step was kept and loaded on the Western blot gel), and proteins were released from the agarose beads by heating at $95^{\circ} \mathrm{C}$ for $5 \mathrm{~min}$ in an SDS-containing buffer. Western blot was performed with the pan-Dlx antibody according to standard procedures.

\section{Slice preparation and time-lapse video imaging}

Sagittal sections $(250 \mu \mathrm{m})$ from virally injected adult (2- to 3-monthold) mouse forebrain were prepared and maintained at $32^{\circ} \mathrm{C}$. Slices were continually superfused $(2 \mathrm{ml} / \mathrm{min})$ with artificial CSF containing the following (in $\mathrm{mm}$ ): $125 \mathrm{NaCl}, 26 \mathrm{NaHCO}_{3}, 10$ glucose, $3 \mathrm{KCl}, 2$ $\mathrm{CaCl}_{2}, 1.3 \mathrm{MgCl}_{2}$, and $1.25 \mathrm{Na}_{2} \mathrm{HPO}_{4}$ (bubbled with $95 \% \mathrm{O}_{2} / 5 \% \mathrm{CO}_{2}$; $\mathrm{pH}$ 7.4). For time-lapse video imaging of cell migration images (at least 6-10 z-sections, with $\sim 10 \mu \mathrm{m}$ interval) were acquired every $15 \mathrm{~s}$ for at least $1 \mathrm{~h}$ with a BX61WI (Olympus) upright microscope equipped with CCD camera (CoolSnap HQ2) and DG-4 Xenon light source (Sutter Instruments). Multiple $z$-step acquisition in our timelapse experiments of cell migration allowed us to follow the same cell in different $z$-planes.

\section{Statistical analysis}

The total number of cells counted in all (injected) animals or experiments is indicated in the text or figure legends. Each animal and each independently performed in vitro experiment represents one " $n$," and SDs were calculated between animals or independent experiments. The only exception to this rule is the statistical analysis of live migration by time lapse videomicroscopy with " $n$ " equaling the number of cells analyzed [the legend to supplemental Fig. 3 (available at www.jneurosci.org as supplemental material) also gives information about the number of slices prepared from different animals in which these cells were analyzed as well as the statistical information]. Error bars are presented as \pm SEM. Comparisons between two groups were performed with the unpaired $t$ test. For comparisons between three treatment groups, a nonparametric ANOVA test was performed. In case three treatment groups were compared over multiple regions, we applied a two-way ANOVA test. Differences between groups were considered significant when $p$ values were smaller than 0.05 .

\section{Results \\ Region-specific expression of Dlx1, Dlx2, Dlx5, and Dlx6 in the adult telencephalon}

To examine the regional expression patterns of Dlx genes, we used in situ hybridization with probes specific for Dlx1, Dlx2, 
Dlx5, and Dlx6 mRNAs. Dlx1 and Dlx2 mRNAs were abundantly expressed in the lateral, but not the dorsal or medial, wall of the lateral ventricle, in the RMS, and in the OB (Fig. $1 A, B$ ). In contrast, neither Dlx5 nor Dlx6 mRNAs were detected within the SEZ, but they started to be expressed at low levels within the RMS, and became abundant in the $\mathrm{OB}$ (Fig. 1C,D) (Levi et al., 2003). This is consistent with the developmental profile of higher expression levels of Dlx 5 and Dlx6 at later stages of cell maturation (Eisenstat et al., 1999). Note that the weak signal present in the white matter of the cerebral cortex is also seen in the sense control and hence reflects background (Fig. $1 E, E^{\prime}$ ). The exclusive expression of Dlx1 and Dlx2 all along the ventrolateral but not the dorsal wall of the lateral ventricle is consistent with the expression pattern during embryonic development and is pronouncedly different from the localization of Pax6 + cells (Fig. 2A). Only some Pax $6+$ cells are located along the lateral wall of the lateral ventricle, and most are detected dorsally and in the RMS (Fig. 2A) (see also Hack et al., 2005). When we used a pan-Dlx antibody (Panganiban et al., 1995; Kohtz et al., 2001; Feng et al., 2004) to reveal Dlx1 or Dlx2 protein in the SEZ (given the absence of Dlx5 and Dlx6 mRNA in SEZ), we observed that the vast majority of cells were only Dlx immunoreactive $(80 \pm 3 \%)$ in the adult SEZ. Only 1 in $10 \mathrm{Dlx}+$ cells also displayed Pax6 immunoreactivity, and a similar proportion of cells within the SEZ expressed only Pax6 (Fig. $2 A^{\prime}, B$ ). In contrast, within the RMS, the majority of cells expressed Pax6, and $20 \%$ coexpressed Pax6 and Dlx (Fig. $\left.2 A^{\prime \prime}, B\right)$. Interestingly, among the DCX+ neuroblasts in the RMS, Dlx + cells predominated (90\%), and an even higher proportion of double-positive cells ( $\sim 40 \%)$ was observed (data not shown). Notably, none of the Dlx TFs was detected in the dentate gyrus at the mRNA or protein level $($ Fig. $1 F, G)$, reminiscent of the absence of these TFs in this dorsomedial region during development. Together, the expression patterns of Dlx and Pax6 genes in the adult telencephalon resemble their regionalization during development.

\section{Identity of Dlx-immunoreactive cells in the SEZ and OB}

Next we characterized the identity of cells expressing Dlx TFs. In the SEZ, Dlx immunoreactivity was absent in GFAP+ cells that comprise the stem cell compartment (Fig. 2C). Fastproliferating BrdU + cells were Dlx + , consistent with previous data (Doetsch et al., 2002). Although astroglia-like stem cells divide rather slowly, they give rise to rapidly dividing transit-amplifying precursors (TAPs), a large proportion of which then generate DCX+ neuroblasts that continue to divide and commence migrating toward the $\mathrm{OB}$. To distinguish
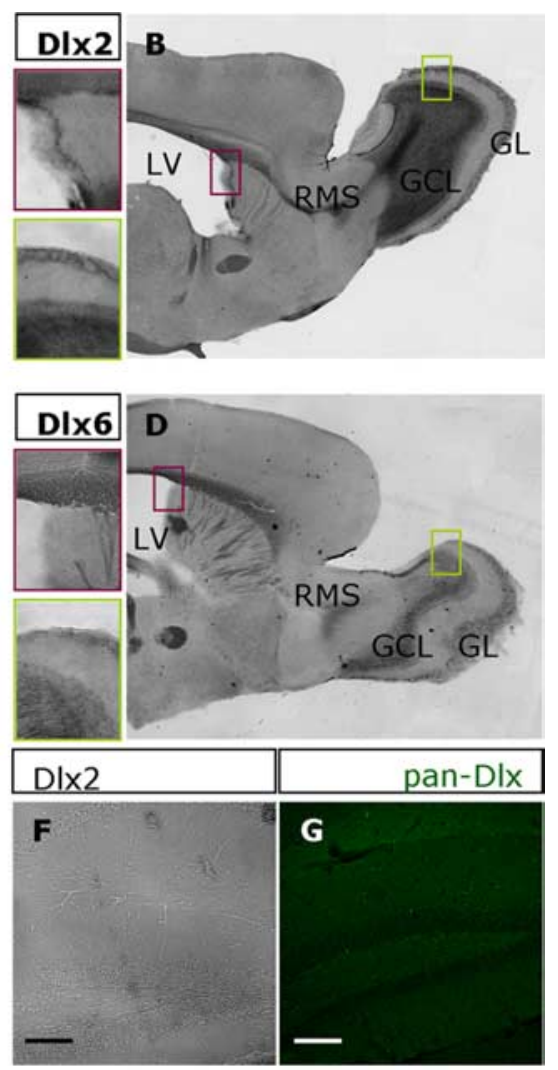

Figure 1. Expression pattern of the Dlx TFs in the adult murine brain. $\boldsymbol{A}-\boldsymbol{D}$, In situ hybridization for Dlx1 $(\boldsymbol{A}), \mathrm{Dlx2}(\boldsymbol{B}), \mathrm{Dlx} 5(\boldsymbol{C})$ and DIx6 (D) mRNA. Note the intense mRNA signal for DIx1 and DIx2 in the adult SEZ in contrast to Dlx5 and DIx6. In the RMS and , D DlX2 in situ hybridization shows no labeling in the SEZ and OB. $\boldsymbol{E}^{\prime}-\boldsymbol{E}^{\prime \prime}$, Higher magnifications of boxed areas. $\boldsymbol{F}$, In situ hybridization for DIx2 mRNA shows no labeling in the dentate gyrus. G, Immunostaining for pan-Dlx (green) in the dentate gyrus shows absence of all TFs of the Dlx family on the protein level. LV, Lateral ventricle; GCL, granule cell layer. Scale bars, $100 \mu \mathrm{m}$.

Dlx expression in TAPs from neuroblasts, we performed triple immunohistochemistry with Dlx, BrdU, and DCX (Fig. 2D) and classified TAPs as BrdU+/DCX-negative and neuroblasts as BrdU+/DCX + cells (TAPs are white and light gray and neuroblasts are black and dark gray in Fig. 2E). Only approximately two-thirds of all TAPs were Dlx + (Fig. 2E), with the remainder expressing the TF Olig2 (Hack et al., 2004, 2005; Menn et al., 2006; Colak et al., 2008) or Mash1 (Fig. 2F) (Parras et al., 2004). Dlx immunoreactivity was not colocalized with Olig2 (Fig. 2G) (Colak et al., 2008), a TF regulating oligodendrogenesis from the SEZ (Hack et al., 2005; Menn et al., 2006; Colak et al., 2008). Dlx immunostaining instead continued to be present in virtually all neuroblasts (Fig. $2 D$ ) as described also for Dlx2 protein (Doetsch et al., 2002).

Within the OB, we noted particularly high Dlx immunoreactivity in the GL (Fig. 3A). PGNs located in this layer consist of 


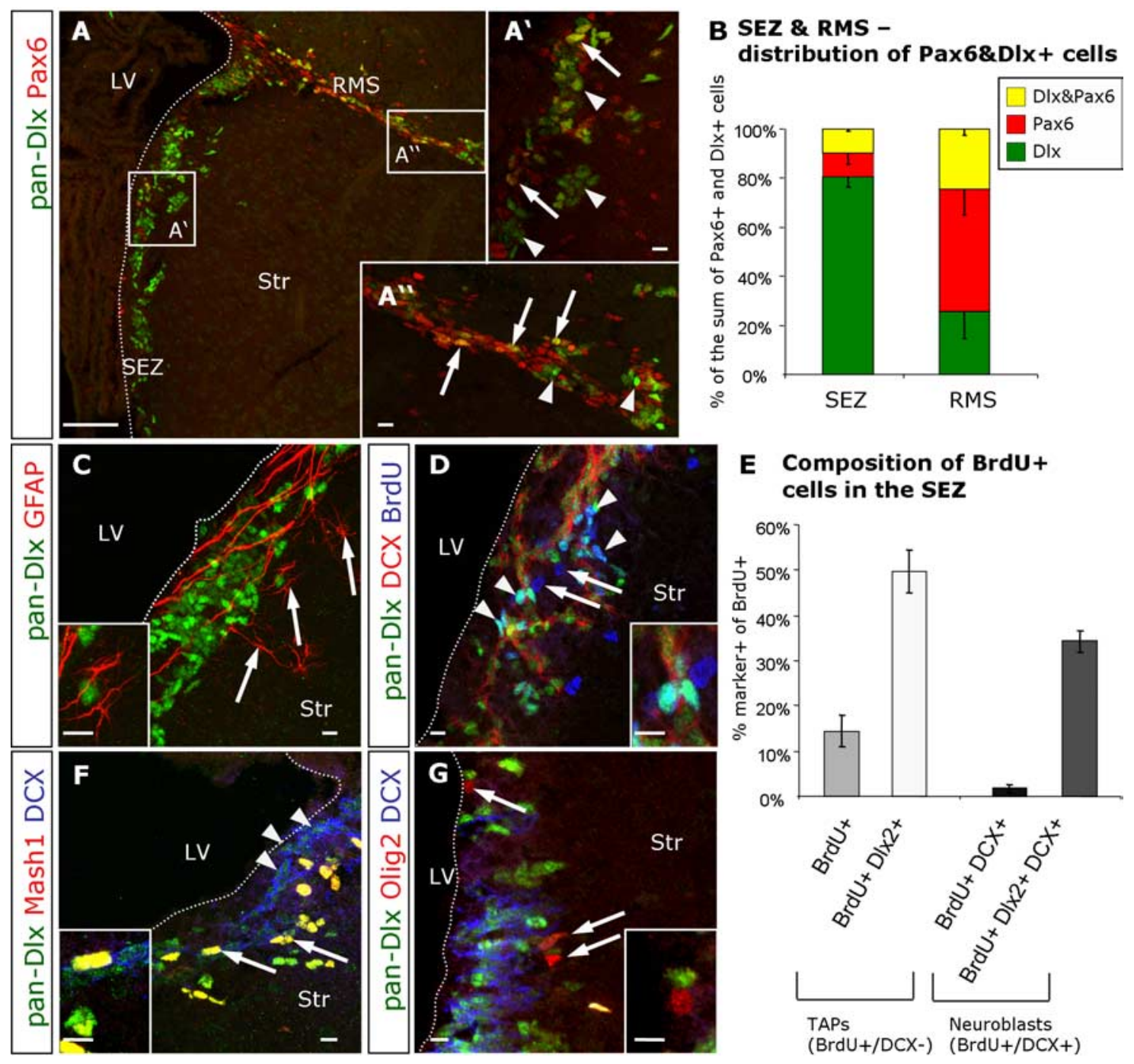

Figure 2. Dlx-immunoreactive cells in the adult SEZ and RMS. A, Overview of the lateral wall of the lateral ventricle (LV) depicting the SEZ and RMS double stained for Dlx (green) and Pax6 (red) proteins. $\boldsymbol{A}^{\prime}, \boldsymbol{A}^{\prime \prime}$, High-magnification images of boxed areas show the SEZ $\left(\boldsymbol{A}^{\prime}\right)$ and the RMS $\left(\boldsymbol{A}^{\prime \prime}\right)$. Arrows indicate double-positive cells, and arrowheads indicate single-positive cells. $\boldsymbol{B}$, Histogram depicting the proportion of cells immunoreactive for only one or both of these TFs. Notably, the proportion of Pax6 + cells and cells immunoreactive for both Dlx and Pax6 increases from the SEZ to the RMS [comparison between SEZ and RMS for Dlx + , Pax6 + , and Dlx $+/$ Pax6,$+ p<0.001$ (ANOVA); number of SEZ cells analyzed $=332 ;$ number of RMS cells analyzed $=363 ; n=3$ animals]. $\boldsymbol{C}, \boldsymbol{D}, \boldsymbol{F}, \boldsymbol{G}$, Example micrographs to identify the cell types expressing Dlx (green) as indicated in the panels. $\boldsymbol{E}$, Histogram depicting the composition of BrdU-positive cells comprising TAPs (white and light gray bars) and neuroblasts (dark gray and black bars) in the SEZ. Note that virtually all neuroblasts are Dlx + , whereas approximately one-fourth of all TAPs are not Dlx + (number of cells analyzed in total $=295 ; n=3$ animals). Scale bars: $A, 100 \mu \mathrm{m} ; \boldsymbol{A}^{\prime}-\mathbf{G}, 10 \mu \mathrm{m} ; \boldsymbol{C}-\mathbf{G}$, insets, $10 \mu \mathrm{m}$. Str, Striatum.

different subtypes, characterized largely by the differential expression of TH and calbindin, two distinct subsets of neurons suggested to be GABAergic (Kosaka et al., 1995; Crespo et al., 1997; Allen et al., 2007; Parrish-Aungst et al., 2007). In contrast, most of the calretinin + PGNs do not contain GABA or GAD65/67 (Kosaka et al., 1995; Allen et al., 2007; Parrish-Aungst et al., 2007) [for colocalization of GAD67 and calretinin, see Panzanelli et al. (2007)]. Interestingly, pan-Dlx immunostaining was confined to most of the calbindin + and virtually all TH + PGNs (Fig. $3 B, C$ ), i.e., the GABA-immunoreactive subtypes, whereas calretinin + PGNs were characteristically devoid of pan-Dlx immunoreactivity (Fig. 3D). Virtually all Pax6+ PGNs also coexpressed Dlx2 (Fig. 3E), suggesting that these factors may interact to specify the dopaminergic neuron fate, as implicated in the developing ventral thalamus (Mastick and Andrews, 2001; Andrews et al., 2003).
Dlx2 acts potently neurogenic in adult SEZ cells in vitro

Because only Dlx1 and Dlx2 are expressed in the SEZ and because they act in a redundant manner, we focused our functional analysis in the remainder of this study on Dlx2. We first performed gain-of-function studies in vitro, by transducing adult SEZderived neurosphere cells with pseudotyped retroviral vectors encoding GFP behind an IRES sequence for control and Dlx2IRES-GFP for Dlx2 overexpression (Fig. 4A). Reliable coexpression of Dlx2 and GFP was confirmed (supplemental Fig. 1, available at www.jneurosci.org as supplemental material). When control-transduced neurosphere cells were examined $7 \mathrm{~d}$ later, the majority of GFP + cells were GFAP + astrocytes, whereas only one-fifth were $\mathrm{Tu} J 1+$ neurons (Fig. $4 B, D$ ). In pronounced contrast, the vast majority of neurosphere-derived cells transduced with Dlx2 acquired a neuronal fate (Fig. $4 C, D$ ), at the expense of the astroglial population. These data suggest that Dlx2 is a potent 
inducer of a neuronal fate in this in vitro model of adult neural stem cells, reminiscent of its function during development (Petryniak et al., 2007).

Next we aimed to examine whether Dlx2 was not only sufficient to instruct neurogenesis, but also required for neurogenesis from adult neural stem cells. Because neurosphere-derived cells generate intrinsically few neurons and are therefore less suitable for a loss-offunction analysis (Fig. 4D), we took advantage of a recently developed culture system for primary adult SEZ-derived cells cultured in the absence of EGF/ FGF2 (Gascon et al., 2005). Indeed, control virus-transduced cells generate a much higher proportion of neurons under these conditions $(\sim 60 \%)$ than cells derived from neurospheres $(\sim 20 \%)$ that have been expanded in the presence of EGF and FGF2 (Fig. 4E; supplemental Fig. $2 B$, available at www.jneurosci.org as supplemental material). Moreover, most cells (except GFAP + astroglia) in the cultures not treated by EGF and FGF2 were Dlx immunoreactive (supplemental Fig. $2 A, A^{\prime}, A^{\prime \prime}$, available at www.jneurosci.org as supplemental material). This allowed us to test the role of endogenous Dlx2, using a retroviral vector encoding a chimeric protein in which the Dlx2 homeodomain had been fused to the Engrailed repressor domain (Fig. 4A) (see Material and Methods), thus converting Dlx2-mediated transactivation into repression (Harris et al., 2003; Woda et al., 2003; Kaji and Artinger, 2004) (Fig. 4A,E). After forced expression of Dlx2-Engrailed in primary SEZ cells, neurogenesis was drastically reduced, whereas GFAP + astrocytes were increased in number (Fig. $4 E$; supplemental Fig. 2C, available at www. jneurosci.org as supplemental material). Conversely, overexpression of Dlx2 resulted in a further increase in neurogenesis, with nearly $90 \%$ of GFP + cells acquiring a neuronal $(\mathrm{TuJ} 1+)$ fate (Fig. $4 E$; supplemental Fig. $2 D$, available at www.jneurosci.org as supplemental material). These data therefore suggest a powerful neurogenic role of Dlx2 in adult stem and progenitor cells.

However, before concluding this, we further examined the specificity of the Dlx2-Engrailed construct, beyond the previous data on the function of Dlx2-Engrailed fusion proteins as repressors and antagonists of the endogenous Dlx2 function (Harris et al., 2003; Woda et al., 2003; Kaji and Artinger, 2004). Because cells isolated from the E13 cerebral cortex contain very few, if any, Dlx $2+$ progenitors cells at this stage, we used them to determine potential off-target effects of Dlx2-Engrailed. E13 cortical progenitors infected with Dlx2-Engrailed still differentiated normally into neurons (control GFP+/TuJ1+, 94.5\%; Dlx2-Eng, $97 \%$; one experiment; number of cells analyzed for control $=618$ and Dlx2-Eng = 355), suggesting that Dlx2-Engrailed transduc- tion does not interfere with neurogenesis in cells that do not express Dlx2 (supplemental Fig. 2E-H, available at www. jneurosci.org as supplemental material). Therefore we conclude that the effect of Dlx2-Engrailed is specific and reveals the need of endogenous Dlx2-regulated targets to be upregulated for neurogenesis to proceed normally.

\section{Dlx2 actspotently neurogenic in adult SEZ cells in vivo}

To examine whether Dlx2 transcriptional activity is also required for adult neurogenesis in vivo, we performed stereotactic injections of the above-described retroviral vectors into the lateral SEZ as described previously (Hack et al., 2005; Colak et al., 2008). The majority of the control-transduced cells analyzed $3 \mathrm{~d}$ postinjection (dpi) into the SEZ were DCX+ neuroblasts (Fig. $5 \mathrm{~A}, \mathrm{E}$ ) (for description of the quantification, see Materials and Methods) and increased even further after forced expression of Dlx2 (Fig. $5 B, E)$. Conversely, the number of DCX + cells was drastically reduced to approximately one-third of the control numbers after transduction with the retrovirus encoding Dlx2-Engrailed (Fig. 
A

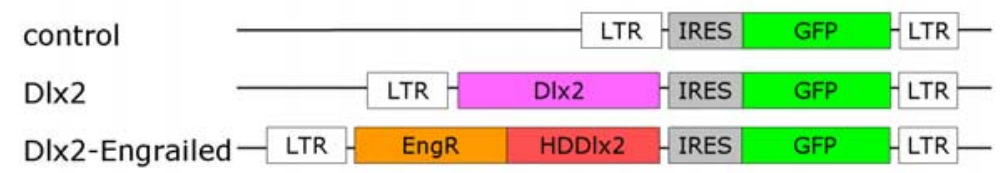
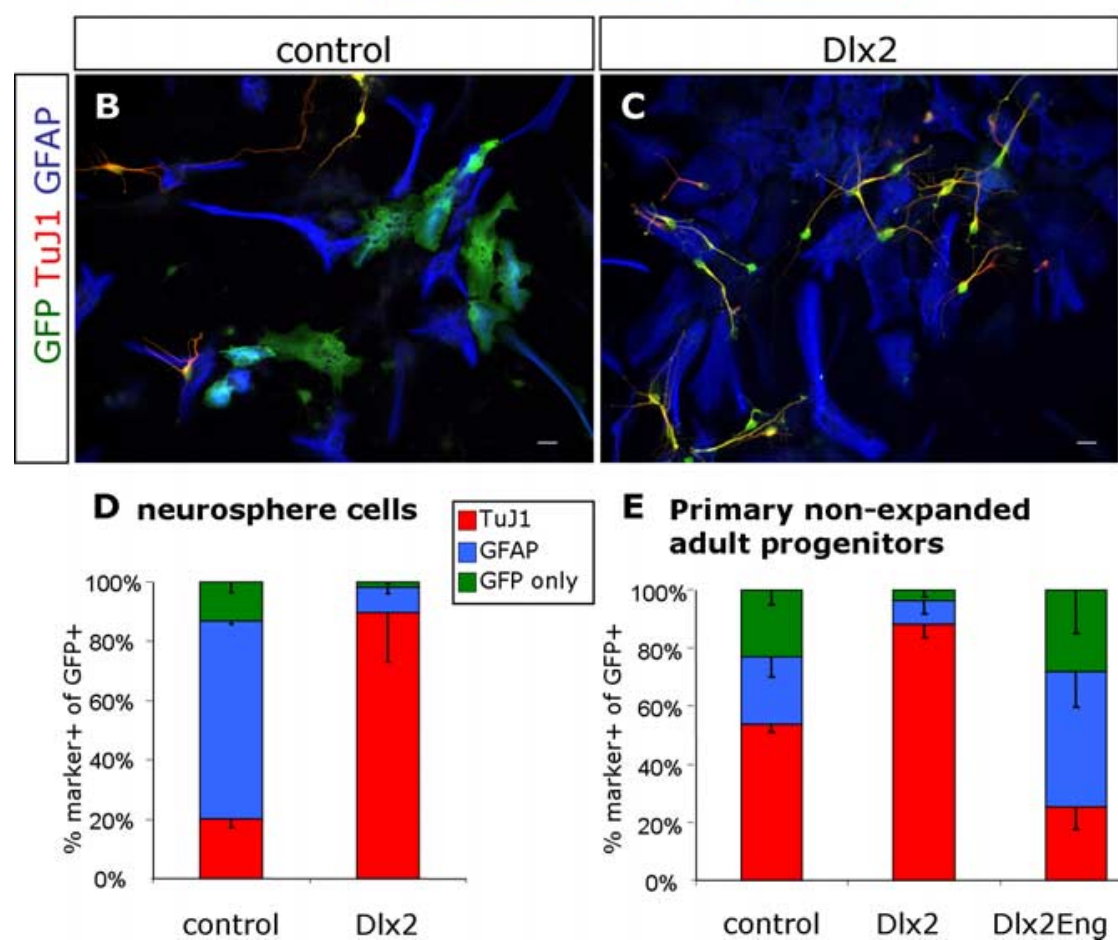

\section{E Primary non-expanded} adult progenitors

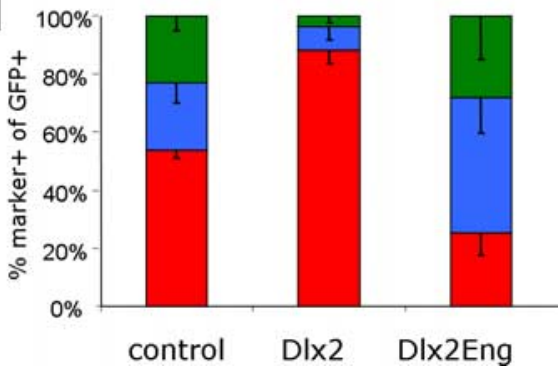

Figure 4. Dlx2 acts potently neurogenic in adult SEZ cells in vitro. $A$, Schematic drawing of the retroviral constructs used for control and manipulation of DIX2. B, C, Fluorescence micrographs of SEZ-derived neurosphere cells after $7 \mathrm{~d}$ of differentiation immunostained for TuJ1 (red), GFAP (blue), and GFP (green). Note the vastly increased number of transduced (GFP+) cells colocalizing with the neuron-specific antigen TuJ1 (red) after Dlx2 overexpression ( $\boldsymbol{C}$ compared with control (B). Scale bars, 10 $\mu \mathrm{m} . \boldsymbol{D}, \boldsymbol{E}$, Histograms depicting the proportion of transduced cells (GFP+) acquiring an astroglial (GFAP + ; blue) or neuronal (TuJ1+; red) fate or neither of these (green) after viral transduction in SEZ-derived neurosphere cells [D; $p=0.03$ (GFAP comparison, $t$ test); $p=0.004$ (TuJ1 comparison, $t$ test); number of control cells analyzed in total = 979; number of Dlx2 cells analyzed in total $=1192 ; n=3$ independent experiments each $]$ or primary nonexpanded adult progenitors $[\boldsymbol{E} ; \mathrm{TuJ} 1+, p<$ 0.001 (ANOVA); number of control cells analyzed in total $=1002$; number of Dlx2 cells analyzed in total $=850$; number of Dlx2-Eng cells analyzed in total $=525 ; n=3$ independent experiments each] after $7 \mathrm{~d}$ of differentiation. Note the potent neurogenic effect of Dlx2 in these adult progenitors.

$5 C, E)$. In contrast, injection of Dlx2-Engrailed-containing virus into the dentate gyrus did not affect neurogenesis in this region (data not shown), further supporting the specificity of this approach.

Dlx2 is required for fast proliferation of SEZ progenitors, but not sufficient to elicit a further increase

To further examine how Dlx2 may affect the number of neuroblasts in the adult SEZ, we considered either a role in neuronal fate specification, given the fast alterations in progenitor fate observed already by $3 \mathrm{dpi}$, or its effect on neuroblast survival and proliferation, respectively. To examine cell death, sections were stained for activated caspase 3, but virtually no caspase $+/$ GFP + cells could be detected, in contrast to the effects seen for Dlx TFs in the retina (de Melo et al., 2008). To examine the proliferation of the transduced cells, we injected BrdU at $3 \mathrm{dpi}, 1 \mathrm{~h}$ before perfusion of the animals (see Material and Methods). After Dlx2 transduction, no difference was detectable in the labeling index, as given by the proportion of BrdU + cells among all GFP + cells (control, $30 \pm 6 \%$; cells counted in total $=243$; Dlx $2,24 \pm 11 \%$; cells counted in total $=229 ; n=4$ animals each group; comparison of control and Dlx2, $p>0.05$, Bonferroni's multiplecomparison test). However, after Dlx2Engrailed transduction, the proportion of BrdU + cells had markedly decreased [ $8 \pm$ $2 \%$; cells counted in total $=140 ; n=3$ animals; comparison of control, Dlx2, and Dlx2-Eng, $p=0.0203$ (ANOVA) and $p<$ 0.05 (Bonferroni's multiple-comparison test)], suggesting that Dlx2-mediated activation of target genes is required for the high proliferative rate of TAPs and neuroblasts. Because, however, proliferation is not required for the increase in neuroblasts caused by Dlx2 overexpression, we conclude that Dlx2 affects directly the neuronal fate decision, while at the same time also being required for regulating progenitor proliferation.

Increase in astrocyte fate after blockade of Dlx2-mediated transcriptional activation in the adult SEZ

Given that Dlx2-Engrailed expression drastically reduces neurogenesis, we next analyzed the identity of the cells generated instead. During embryonic development, deletion of Dlx1 and Dlx2 results in a fate switch from neurogenesis to oligodendrogenesis (Petryniak et al., 2007). Therefore, we examined the TF Olig2, a key determinant of oligodendrocyte fate in development (Lu et al., 2002; Rowitch, 2004) and adulthood (Hack et al., 2005; Menn et al., 2006; Colak et al., 2008). Accordingly, already at 3 dpi we observed an eightfold increase in the number of GFP+/Olig2+ cells (Fig. 5E), as well as in the number of cells coexpressing NG2, an antigen commonly detected on oligodendrocyte progenitor cells $[\mathrm{NG} 2+$ : control, $0.7 \pm 0.2 \%$; Dlx2-Eng, $12 \pm 5 \% ; p=0.017$ ( $t$ test); control, $n=4$ animals; Dlx2-Eng, $n=3$ animals], suggestive of an apparent increase in oligodendroglial fate decision. However, also the number of cells coexpressing GFP and GFAP was increased by fivefold (Fig. $5 E$ ). Indeed, the astrocytic progeny derived from Dlx2-Engrailed-transduced cells continued to increase in number when assessed at later stages $(21 \mathrm{dpi})$. Three weeks after Dlx2-Engrailed injection, the SEZ became virtually devoid of GFP+ neuroblasts, whereas now the population labeled by GFAP had become predominant among all Dlx2Engrailed-transduced cells (Fig. 6A,B). Compared with the $3 \mathrm{~d}$ analysis, the proportion of Olig2 + and NG2 + cells among the $\mathrm{GFP}+$ cells had remained relatively constant (Figs. 5E, 6A,C) [Olig2+: Dlx2-Eng 3 dpi, $35 \pm$ 5\%; Dlx2-Eng 21 dpi, $31 \pm 6 \%$; $p=0.8048$ ( $t$ test); NG2+: Dlx2-Eng 3 dpi, $12 \pm 5 \%$; Dlx2-Eng 21 dpi, $8 \pm 2 \% ; p=0.2526$ ( $t$ test); $n=3$ animals for 3 dpi and $n=4$ animals for $21 \mathrm{dpi}$. However, a small but significant increase in the number of oligodendrocytes, identified by the antigen Adenomatous polyposis coli (APC+) (McTigue et al., 2001; Ding et al., 2003; Malatesta et al., 2003), could be observed after interference with Dlx2-mediated transactivation (Fig. 6A,D,E), 
suggestive of some increase in oligodendrogliogenesis that had been initiated already $3 \mathrm{~d}$ after transduction, as visible by the increase in olgiodendroglial progenitors, and then these cells further proceeded to mature into APC+ oligodendrocytes. Intriguingly, however, the proportion of oligodendrocyte progenitors did no longer increase between 3 and $21 \mathrm{~d}$ after transduction with Dlx2-Eng, but rather GFAP + cells then increased in number.

Normally, oligodendrocyte progenitors leave the SEZ and migrate toward the corpus callosum (CC), where they differentiate into mature oligodendrocytes (Hack et al., 2005; Menn et al., 2006; Colak et al., 2008). To examine whether these cells are increased in number after Dlx2Engrailed transduction, we monitored the position of GFP + cells by quantifying the proportion of all GFP + cells (21 dpi) located in the OB, RMS, SEZ, or CC as described before (Hack et al., 2005; Colak et al., 2008). Whereas most cells derived from SEZ cells transduced with the control virus had reached the OB $21 \mathrm{dpi}$, and their number further increased after Dlx2 transduction, only $42 \pm 6 \%$ of cells transduced with the Dlx2-Engrailed virus had reached the OB (Fig. 6F). Thus, the majority of Dlx2-Engrailed-transduced cells fail to migrate toward the $\mathrm{OB}$, and most of these remain in the SEZ (Fig. $6 F$ ). Some of the Dlx2-Engrailed-transduced cells had also migrated to the CC, and although their proportion was small, it was significantly increased compared with that of the control virus-transduced cells (Fig. $6 F$ ). Interestingly, however, this does not mean that all of these cells became oligodendrocytes, because even among the cells that had reached the CC after Dlx2-Engrailed transduction, we found some GFAP+ astrocytes (Fig. 6G). Thus, interference with Dlx2-mediated transcriptional activation results in virtual absence of neuroblast generation by 3 weeks, but favors mostly the generation of GFAP + cells, a notable difference from the effect of Dlx2 deletion during embryonic development.

\section{Dlx2 promotes but is not required for migration of adult SEZ and RMS progenitors}

Because Dlx2-Engrailed-transduced cells remained largely in the SEZ, and Dlx TFs regulate migration of embryonic neuroblasts (Cobos et al., 2007; Le et al., 2007), we monitored the migration of transduced cells by live time-lapse microscopy (see Material and Methods). Only cells exhibiting migratory behavior were included in the analysis, thereby excluding both dead and nonmigrating cells (Nam et al., 2007). Control and Dlx2- and Dlx2Engrailed-containing retroviral vectors were injected into the SEZ and RMS, and acute slices of the adult mouse forebrain were prepared $5 \mathrm{~d}$ later. Time-lapse video imaging of transduced cells in the SEZ and RMS revealed that Dlx2 transduction increased the velocity of migration by $\sim 30 \%$ compared with controls (supplemental Fig. $3 A$, B and movies of control- and Dlx2-transduced cells, available at www.jneurosci.org as supplemental material; for statistics and cell numbers, see figure legend). As a consequence of the increased velocity, the mean distance that cells

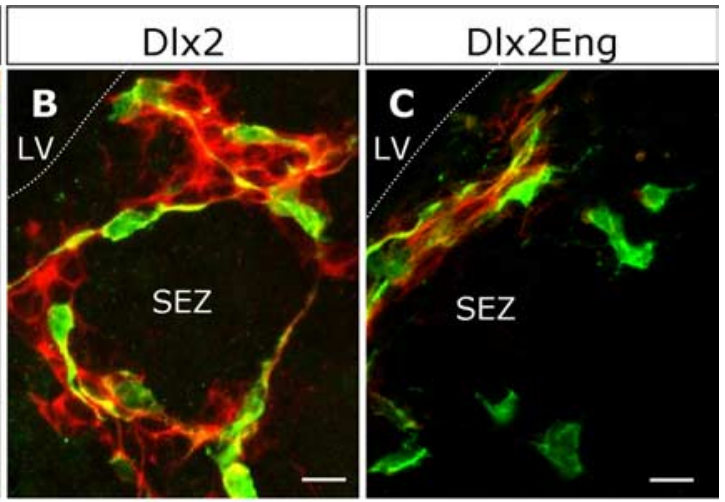

E composition of cell types - 3dpi

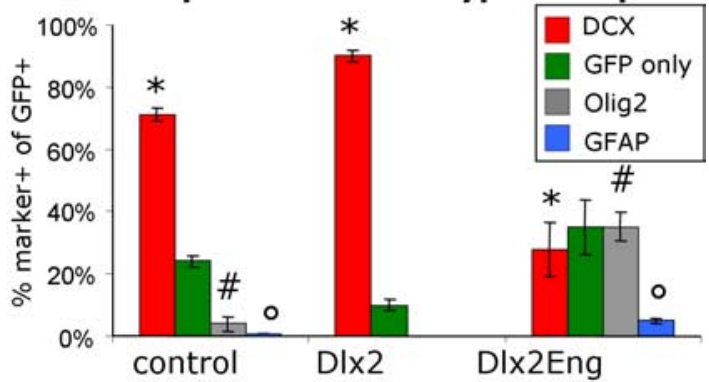

DIx2Eng

Figure 5. Dlx2 acts potently neurogenic in adult SEZ cells in vivo. $\boldsymbol{A}-\boldsymbol{D}$, Representative examples of micrographs depicting transduced (GFP +) cells after stereotactic injections of control $(\boldsymbol{A})$, Dlx2 $(\boldsymbol{B})$, and Dlx2-Engrailed $(\boldsymbol{C})$ retroviral vectors into the control $=243$, Dlx2 $=229, n=4$ animals each; Dlx2-Eng $=349, n=3$ animals; significance of $p<0.05$ is indicated by the following symbols: ${ }^{*}{ }^{\circ}$, and \#]. Scale bars, $10 \mu \mathrm{m}$. LV, lateral ventricle.

propagated increased after Dlx2 overexpression (supplemental Fig. 3C, available at www.jneurosci.org as supplemental material). Thus, Dlx2 overexpression promotes migration of cells in both RMS and SEZ. In contrast, GFP + cells transduced with Dlx2-Engrailed were not significantly altered in their speed of migration (supplemental Fig. $3 B$, available at www.jneurosci.org as supplemental material). These data therefore suggest that Dlx2 promotes migration of neuroblasts and that the high number of cells remaining in the SEZ after Dlx2-Engrailed transduction is not attributable to migration deficits, but rather fate and proliferation changes.

\section{Dlx2 promotes dopaminergic $P G N$ fate in the adult $O B$}

As mentioned above, Dlx2 expression is maintained at particularly high levels in PGNs, prompting us to examine its later role in neuronal subtype specification. Because we had previously observed that viral injections into the SEZ do not result in substantial numbers of neuronal progeny populating the GL, we injected the viral vectors into the RMS (Fig. 7A) (Hack et al., 2005). After Dlx2 overexpression, we observed an approximately threefold increase in the proportion of neurons populating the GL compared with control injections (Fig. 7B). Next, we examined whether the increased number in PGNs was biased toward a specific subtype. After injection of the control virus into the RMS, $4 \pm 1 \%$ of all GFP + PGNs were calbindin,$+ 18 \pm 0.5 \%$ calretinin + , and $7 \pm 0.75 \% \mathrm{TH}+$. After Dlx 2 overexpression, we detected a profound increase (fourfold) in the proportion of $\mathrm{TH}+$ PGNs, mostly at the expense of the calretinin + PGNs (Fig. 7C$F$ ). Notably, no TH+ PGNs could be observed among the few PGNs detectable after transduction with Dlx2-Engrailed (data 


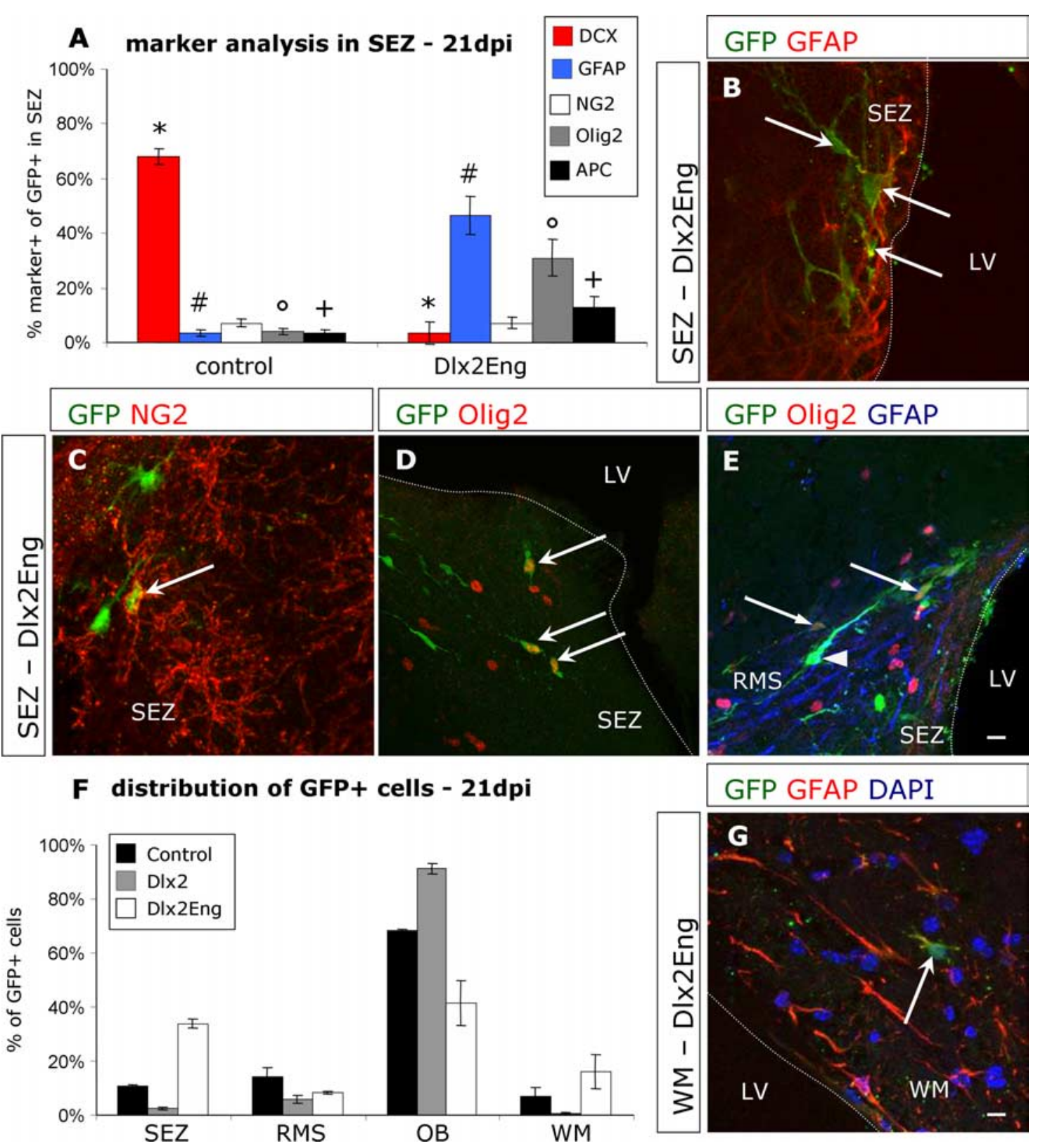

Figure 6. Increase in astrocyte fate after blockade of Dlx2-mediated transcriptional activation in the adult SEZ. A, Quantification of transduced cells within the SEZ after a survival time of 3 weeks (21 dpi) after injection with viruses encoding GFP or Dlx2-Engrailed. The proportion of GFP+/GFAP+ (blue) cells increased strongly after Dlx2-Engrailed injection, mostly at the expense of GFP/DCX + (red) neuroblasts. The number of Olig2 + cells (gray) remained similar, and a slight increase in the number of NG2 + (white) and APC + (black) cells was observed [DCX,$+ p<0.001$ ( $t$ test); NG2,$+ p=0.7825$ ( $t$ test); Olig2,$+ p<0.001$ ( $t$ test); APC,$+ p=0.0218$ ( $t$ test); number of cells analyzed in total: control $=68 ;$ Dlx2-Eng $=98 ; n=4$ animals each; significance of $p$ $<0.05$ is indicated by the following symbols: ${ }^{*}, \#,{ }^{\circ}$, and + ). $\boldsymbol{B}-\boldsymbol{E}, \mathbf{G}$, (ellular identities of the progeny after Dlx2-Engrailed transduction shown in immunohistochemistry for GFP (green) and specific markers as indicated in the panels; of note, GFP +/Olig2 + cells indicated by arrows do not colocalize with GFP +/GFAP + cells shown by arrowhead in $\boldsymbol{E}$; $\boldsymbol{B}-\boldsymbol{D}$, arrows indicate GFP +/marker + cells. Scale bars, $10 \mu \mathrm{m}$. $\boldsymbol{F}$, Quantification of the distribution of cells $21 \mathrm{dpi}$ into the SEZ. The proportion of transduced GFP + cells located in the SEZ, RMS, OB, and CC was quantified. The majority of control-transduced cells had reached the $0 B$ with their number further increased after Dlx2 transduction. Conversely, only $42 \%$ of Dlx2-Eng-transduced cells reached the $0 B$. Of note, the proportion of transduced cells remaining in the SEZ increased after Dlx2-Engrailed transduction $[p<0.001$ (2-way ANOVA comparison of all regions and groups); number of control cells analyzed in total $=$ $376 ; n=4$ animals; number of Dlx2 cells analyzed in total $=344 ; n=3$ animals; number of Dlx2-Eng cells analyzed in total $=195 ; n=3$ animals]. LV, Lateral ventricle; WM, white matter.

not shown). Given the fact that TH-expression is known to increase with maturation (Brunjes, 1994; Winner et al., 2002; Hack et al., 2005), we examined whether Dlx2 overexpression had only accelerated the expression of TH or had indeed permanently increased the proportion of this neuronal subtype. Consistent with the gradual maturation of TH expression, 8 weeks after control injections into the RMS, the proportion of TH+ neurons had increased to $29 \pm 3 \%$ (from $7 \%$ after 3 weeks). However, after Dlx2 overexpression, a larger number of PGNs still expressed TH, indicating that Dlx2 had not merely accelerated maturation, but permanently altered neuronal subtype acquisition (Fig. $7 F$ ). Thus, Dlx2 overexpression promotes the acquisition of a periglomerular neuronal fate with a strong bias toward the dopaminergic subtype.

\section{Dlx2 requires Pax6 to promote dopaminergic PGN fate}

Because the above results obtained with Dlx2 manipulation were highly reminiscent of our previous results with Pax6 (Hack et al., 2005), we were prompted to ask whether Dlx2 indeed requires 
Pax6 in OB neuronal subtype specification or whether it acts redundantly with Pax6, in particular because both TFs are coexpressed in the TH+ PGNs (Fig. 3E). To clarify this issue, we examined the effect of Dlx2 overexpression in the absence of Pax6 protein. To delete Pax6, we injected a virus encoding Cre recombinase (CreIRES-GFP) into mice in which the Pax6 gene had been flanked with loxP sites (before exon 4 and at an intron between exon 6 and 7) (Ashery-Padan et al., 2000; Hack et al., 2005). As previously shown, injection of Cre-encoding virus allows the efficient deletion of Pax6 in adult progenitors (Fig. $8 A$; supplemental Fig. 4, available at www.jneurosci.org as supplemental material) (Ashery-Padan et al., 2000; Hack et al., 2005). To examine the effect of Dlx2 overexpression on PGN fate after Cremediated deletion of Pax6, we performed coinjections of the Dlx2-encoding virus (Dlx2-IRES-DsRed) together with either a control virus or the Cre-encoding virus into the RMS and examined their respective progenies labeled by green only, red only, or red and green 3 weeks later (Fig. $8 B, C)$. Transduction with the Dlx2encoding virus reproducibly resulted, as expected, in a profound increase in the proportion of PGNs (Fig. $8 \mathrm{~B}-\mathrm{F}$; for overview, see $D, E)$. Strikingly, however, the effect of Dlx2 overexpression was totally abrogated in the absence of Pax6, i.e., in cells double infected with the Cre- and Dlx2-encoding viruses (Fig. 8F). Thus, Dlx2 requires Pax6 to instruct PGN fate.

Similar results were obtained when PGN subtypes were examined. After transduction with a Cre-encoding virus, the proportion of $\mathrm{TH}+$ neurons among all PGNs decreased [control, $7 \pm 1 \%$; Cre, $1 \pm 0.8 \%$; control cells counted in total $=$ 126; Cre cells counted in total $=111 ; n=3$ animals each; $p=0.035$ ( $t$ test)], whereas the relative contribution of calretinin + cells to the total population of PGNs increased [from $16 \pm 4 \%$ after control virus transduction to $76 \pm 4 \%$ after Cre virus transduction; $p<0.001$ ( $t$ test); control cells counted in total $=189$; Cre cells counted in total $=206 ; n=4$ animals each]. These data suggest that in the absence of Pax6, already specified PGNs fail to adopt a dopaminergic fate, switching predominantly to a calretinin + phenotype instead. Of note, the proportion of calbindin + cells was hardly affected [control, $3 \pm 2 \%$; Cre, $4 \pm 2 \%$; Cre plus Dlx2, $2 \pm 1.5 \% ; p=0.3679$ (ANOVA); control cells counted in total $=92$; Cre cells counted in total $=138$; Cre plus Dlx2 cells counted in total $=63 ; n=4$ animals each]. Notably, the increase in calretinin + PGNs among the PGNs after Crecontaining virus infection and Pax6 deletion could no longer be reverted by Dlx2 overexpression when it had coinfected Cre-
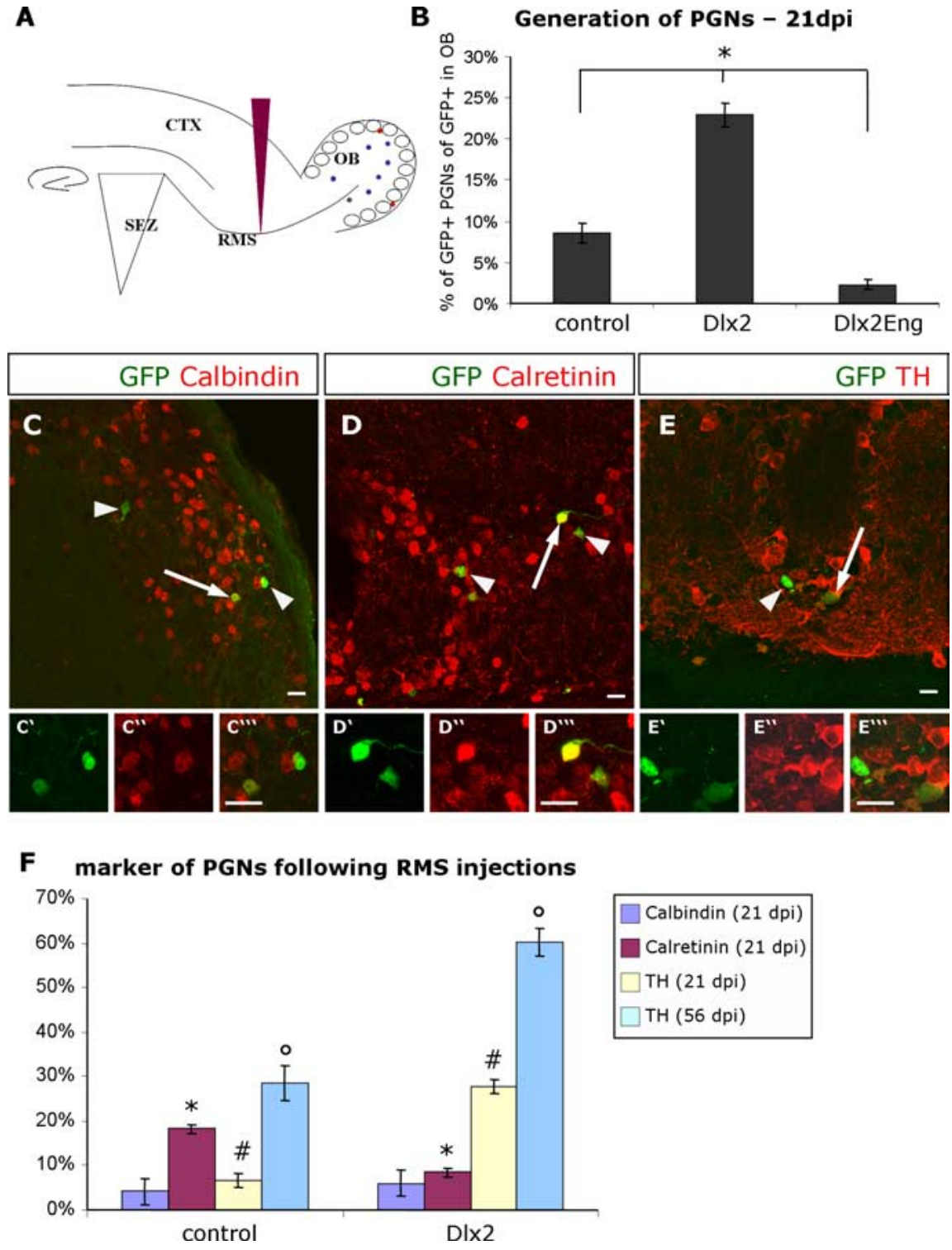

Figure 7. Dlx2 promotes a dopaminergic PGN fate in the adult OB. $A$, Schematic drawing of a sagittal mouse brain section with a red arrow indicating the injection site. $\boldsymbol{B}$, Histogram depicting the proportion of newly generated PGNs among the GFP + cells transduced with control, DlX2, or Dlx2-Engrailed viral vectors injected into the RMS. Significantly more PGNs are generated after DIx2 transduction, whereas their number decreased after DIx2-Engrailed transduction [control, $n=5$ animals; D|x2, $n=4$ animals; Dlx2-Eng, $n=2$ animals; number of cells analyzed in total: control $=3158$; Dlx2 $=2185$; Dlx2-Eng $=148$; ${ }^{*} p<0.001$ (ANOVA)]. $\boldsymbol{C}-\boldsymbol{E}$, Fluorescent micrographs showing representative examples of transduced PGNs: GFP (green) and calbindin ( $\boldsymbol{C} ;$ red), calretinin ( $\boldsymbol{D}$; red), and TH (E; red). Note that all three types of PGNs are generated after retroviral transduction. Arrows highlight positive cells; arrowheads indicate marker-negative cells. $\boldsymbol{C}^{\prime}-\boldsymbol{C}^{\prime \prime}, \boldsymbol{D}^{\prime}-\boldsymbol{D}^{\prime \prime \prime}, \boldsymbol{E}^{\prime}-\boldsymbol{E}^{\prime \prime \prime}$, Higher magnifications of the accordant markers. $\boldsymbol{F}$, Histogram showing composition of GFP + PGNs. Calbindin + /GFP + PGNs remained constant in the control and Dlx2 transduction. However, the proportion of TH + PGNs after DIx2 transduction increased strongly, mostly at expense of the calretinin +/GFP + PGNs [21 d: calbindin +, $p=0.3669$ ( $t$ test); calretinin,$+ p=0.0235$ ( $t$ test); TH,$+ p<0.001 ; n=3$ animals each group; number of cells analyzed in total: control $=336$; Dlx2 $=412 ; 56 \mathrm{~d}$ : TH,$+ p<0.001$ ( $t$ test); number of cells analyzed in total: control $=174 ;$ Dlx2 $=76 ; n=4$ animals each group; significance of $p<0.05$ is indicated by the following symbols: ${ }^{*}$, \#, and ${ }^{\circ}$. Scale bar, $10 \mu \mathrm{m}$. CTX, Cortex.

transduced cells $(76 \pm 5 \%$ calretinin + cells among the doubleinfected cells; cells counted in total $=105 ; n=4$ animals), and no $\mathrm{TH}+$ neurons were detected either (Cre plus Dlx2 cells counted in total $=68 ; n=4$ animals). Thus, Dlx2 requires Pax6 to promote the dopaminergic PGN subtype identity.

\section{Molecular interaction between Pax6 and Dlx2}

At the molecular level, this result could be explained by two scenarios: (1) both TFs may cooperate by mutually regulating their 
A
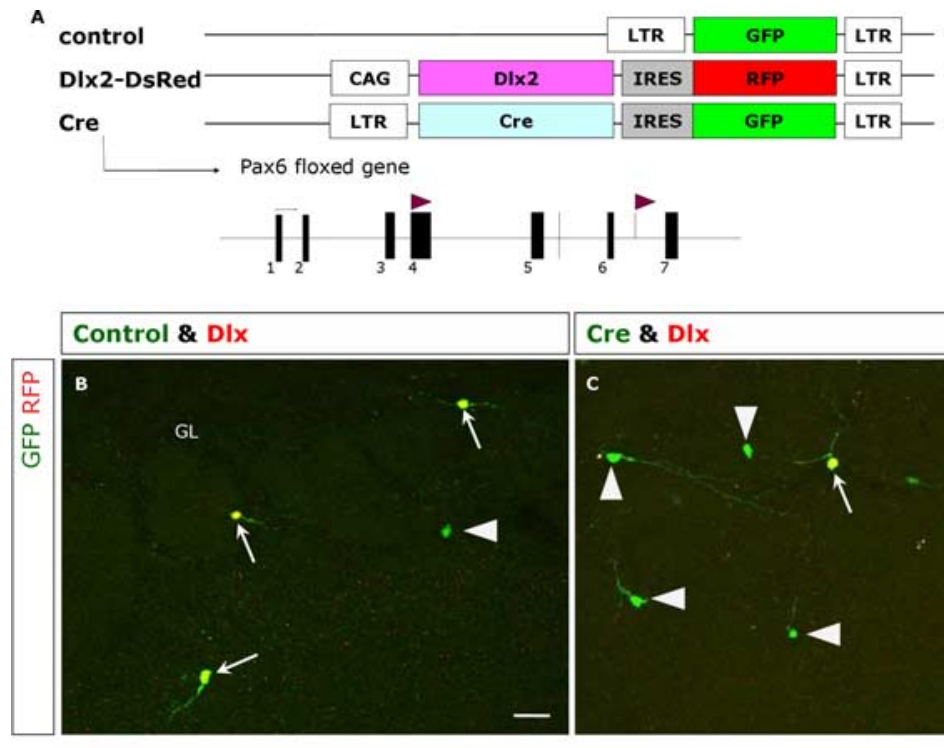

\section{Cre \& DIx}
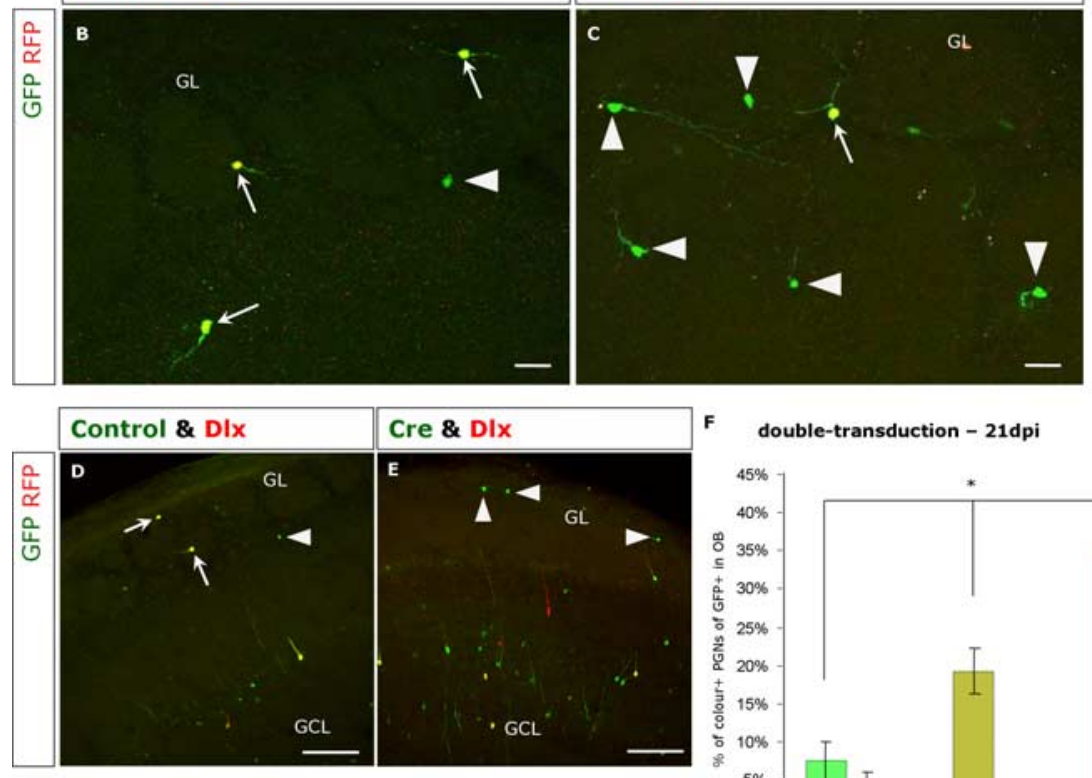

G

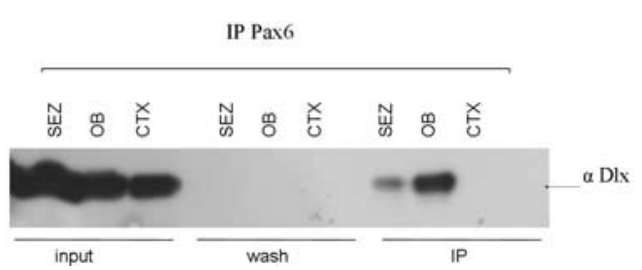

Figure 8. DIx2 requires Pax6 to promote a dopaminergic PGN fate. $A$, Schematic drawing of the retroviral constructs used for control, overexpression, and Cre-mediated deletion of Pax6 in mice in which exons $4-6$ of the Pax 6 gene had been flanked by loxP sites (construct indicated on the bottom with violet triangles indicating loxP-sites and black rectangles for exons). Note that the construct for Dlx2 overexpression is followed by an IRES-DsRed cassette. $\boldsymbol{B}-\boldsymbol{E}$, Injections of the above constructs $(\boldsymbol{A})$ into the RMS resulted in green (control or $(\mathrm{re}$ ) and yellow (cotransduced with DIx2-DsRed) cells in the OB. Note the decreased generation of yellow PGNs (depicted by arrows) after loss of Pax6 protein in the GL. Arrowheads depict only green PGNs. F, Quantification of newly generated PGNs 21 dpi after injection into the RMS of either control and red Dlx2 virus or Cre and red Dlx2 virus into homozygous Pax6 floxed mice [ $p<0.001$ (ANOVA), group comparison of control only, control plus Dlx2DsRed and Dlx2DsRed only, and control plus Dlx2DsRed with Dlx2DsRed only; $p>0.05$, Bonferroni's multiple-comparison test between control plus Dlx2DsRed and Dlx2DsRed only; $p<0.05$, Bonferroni's multiple-comparison test between control only and control plus DIx2DsRed; number of control and DIx2-Red cells analyzed in total $=4678$; number of Cre and DIx2-Red cells analyzed in total = $3024 ; n=4$ animals each]. Notably, the generation of PGNs could not be rescued by DIx2 overexpression after Cre-mediated deletion of Pax6. G, Coimmunoprecipitation of Dlx by Pax6. Western blot for pan-Dlx on Pax6-precipitated total lysates of SEZ, OB, and CTX. No signal for Dlx proteins was detected in the wash fraction or immunoprecipitates from the cerebral cortex, whereas Dlx TFs were pulled down by Pax6 antibody in lysates prepared from both the SEZ and, even more strongly, the OB. IP, Immunoprecipitates; GCL, granule cell layer; CTX, cortex. Scale bars: $\boldsymbol{B}, \mathbf{C}, 20 \mu \mathrm{m} ; \boldsymbol{D}, \boldsymbol{E}, 100 \mu \mathrm{m}$.

expression, albeit otherwise controlling a specific set of different target genes; or (2) they may interact directly, for instance by partaking in the same transcriptional complex. To investigate whether Pax6 is a target of Dlx2, we overexpressed this TF in neurosphere cells. However, no increase in the number of Pax6expressing cells was found after this manipulation (supplemental Fig. 5, available at www.jneurosci.org as supplemental material). Also, the converse held true; namely, no increase in the number of Dlx + cells was observed after Pax6 transduction in these cells (supplemental Fig. 5, available at www.jneurosci.org as supplemental material). Of note, similar results were obtained when analyzing the Dlx2-GFP-transduced cells in vivo: neither in the SEZ nor in the OB were all Dlx2-transduced cells Pax6+, as expected if Dlx2 would upregulate Pax6. Thus, it appears that at least in this cellular context, these TFs do not cross-regulate each other's expression, a finding also consistent with the heterogeneity of Dlx-only, Pax6-only, and Dlx/Pax6-double-positive cells in vivo (Fig. $2 A$ ).

Thus, Pax6 and Dlx TFs appear to be regulated independently, but may act concertedly when contained in the same cells. To test this hypothesis and in particular the possibility that these TFs partake in the same transcriptional complex, we performed an immunoprecipitation analysis. Total lysates were prepared from adult mouse SEZ, OB, and cerebral cortex and were immunoprecipitated with a mouse monoclonal anti-Pax6 antibody, and Dlx protein was then revealed by Western blot analysis of these precipitates (Fig. 8G). Although no signal for Dlx proteins was detected in the wash fraction or immunoprecipitates from the cerebral cortex (where Pax6 and Dlx2 do not colocalize in the same cells), Dlx TFs were found to be pulled down by Pax6 precipitation of lysates prepared from both the SEZ and, even more strongly, the OB. These data therefore suggest that Dlx proteins and Pax6 physically interact and require each other to exert some of their key functions in adult neurogenesis.

\section{Discussion}

In the present study, we demonstrate two key functions of Dlx2 in the adult SEZ, namely its roles in neurogenesis and in neuronal subtype specification. Cellautonomous manipulations by viral vectors demonstrate that Dlx2 potently promotes the specification of neuroblasts and regulates neuronal subtype specification favoring a dopaminergic PGN fate. Notably, the latter effect occurs by a cooperation of Dlx2 and Pax6 at the expense of the calretinin + PGN fate.

Function of Dlx2 in adult neurogenesis Dlx2 overexpression in SEZ progenitors resulted in a larger number of neuroblasts among the infected cells, because of an increase in neuronal specification, but not proliferation. Moreover, a larger proportion of Dlx2-transduced cells reached the $\mathrm{OB}$, because of an increase in migration velocity. The potent neurogenic effect of Dlx2 in adult SEZ-derived neurosphere cells further supports the conclusion that Dlx2 is sufficient to instruct progenitors to acquire a neuronal fate. Accordingly, Dlx2-Engrailed transduction causes a severe decline of 
neuroblasts both in vivo and in vitro. Dlx2-Engrailed primarily suppresses those genes that would normally be activated by Dlx2, but possibly also affects targets of Dlx1. Because little is known about the targets of these TFs or the proteins with which they interact to regulate their targets, we cannot exclude that Dlx2Engrailed may also act on Dlx1-regulated genes. The possible compensation for the loss of Dlx 2 by Dlx1 as observed in mice with targeted deletion of these genes individually (Qiu et al., 1995; Anderson et al., 1997) prompted us to take this approach rather than a protein knock-down that may require elimination of both Dlx1 and Dlx2. Our results demonstrate that Dlx2and/or Dlx1-activated target genes are essential for progression toward a neuroblast lineage and for initiation or maintenance of a high proliferation rate. Indeed, the latter role fits well with the early expression of Dlx2 in TAPs (Doetsch et al., 2002).

In the light of our data on the neurogenic function of Dlx2 in adult SEZ progenitors, the expression of Dlx TFs in only a subset of TAPs (Colak et al., 2008) suggests that the neurogenic lineage becomes already determined at the TAP stage. The existence of two subtypes of TAPs, characterized by the mutual exclusive expression of Olig2 and Dlx1 and Dlx2 under physiological conditions, suggests that these cells belong to distinct lineages. In contrast to the observations in the adult SEZ, substantial coexpression of Dlx1 and Dlx2 and Olig2 occurs in the embryonic ventral telencephalon, where a common oligodendrocyte/ interneuron precursor has been identified (Miyoshi et al., 2007; Petryniak et al., 2007). Here, specification toward the neuronal lineage appears to occur via a gradual Dlx1- and Dlx2-mediated downregulation of Olig2, whereas the lack of coexpression of these TFs in the adult SEZ suggests that other mechanisms are involved in the suppression of Olig2. Indeed, we found that in the adult SEZ, BMP-mediated signaling, which is conspicuously absent in the developing ventral telencephalon (Shimogori et al., 2004; Fernandes et al., 2007), is required for Olig2 suppression (Colak et al., 2008). Thus, in addition to similarities, there are important differences in the precise molecular mechanisms involved in neuronal versus oligodendroglial fate specification in the developing and adult telencephalon. Indeed, many adult SEZ progenitors adopt an astroglial identity after expression of Dlx2Engrailed, whereas most cells deficient of Dlx1 and Dlx2 in the developing telencephalon revert to an oligodendroglial fate (Petryniak et al., 2007). Intriguingly, adult neural stem cells are of astroglial identity (Alvarez-Buylla et al., 2001), and we observed a certain proportion of GFAP +, Dlx2-Engrailed-transduced cells incorporating BrdU, suggesting that some progenitors, when inhibited from progressing toward neurogenesis, revert to a stem cell fate.

\section{Function of Dlx 2 in neuronal subtype specification}

In addition to its role in generic neurogenesis, Dlx2 exerts an important function in neuronal subtype specification, promoting the acquisition of a PGN identity, in particular of the dopaminergic subtype. Notably, these effects of Dlx2 are virtually identical to those of Pax6 (Hack et al., 2005). As in the case of Dlx2, overexpression of Pax6 results in increased neurogenesis, whereas interfering with Pax6 function inhibits neurogenesis. Moreover, Pax6 promotes the subtype specification of dopaminergic PGNs (Hack et al., 2005; Kohwi et al., 2005). These findings are suggestive of a cooperation of these TFs. Although we found no evidence for either of these factors regulating expression of the other in adult SEZ-derived cells, coimmunoprecipitation of Pax6 and Dlx proteins demonstrated their physical interaction. More strikingly, in the absence of Pax6 protein, Dlx2 no longer promotes the acquisition of a PGN fate, demonstrating that Pax6 and Dlx2 are each required for the specification of $\mathrm{TH}+$ PGNs. Cells double positive for Dlx2/Pax6 increase from $\sim 10 \%$ in the SEZ to $20 \%$ in the RMS, suggesting that some of the TH+ cells are already generated in the SEZ. The proportion of doublepositive cells is even higher considering only the neuroblast population reaching $\sim 40 \%$. This higher percentage of doublepositive cells within the RMS is consistent with our previous findings that the RMS contains most of the stem/progenitors giving rise to $\mathrm{PGNs}$, including dopaminergic neurons in mice (Hack et al., 2005) and in rat (Mendoza-Torreblanca et al., 2008). However, the proportion of PGNs resulting from RMS injections is only $10 \%$ after 3 weeks and even smaller for the proportion of $\mathrm{TH}+$ neurons among these. This could be explained by a large fraction of the newly arriving neurons undergoing cell death, or by Pax6 and Dlx 2 cooperating on a broader fate specification that is then further refined by extrinsic signals within the OB.

Thus, the present and previous studies suggest the following transcriptional code for the specification of PGNs: (1) calretinin + PGNs lack Pax6 and Dlx, but express Sp8 (Waclaw et al., 2006); (2) calbindin + PGNs contain Dlx and Meis2 (Allen et al., 2007), but not Pax6; and (3) dopaminergic PGNs contain both Dlx and Pax6 [and Meis2 and Er81 (Allen et al., 2007)]. Our functional analysis highlights the necessity for Pax6 and Dlx coexpression and collaborative function for the specification of dopaminergic PGNs. In the absence of the function of either Pax6 or Dlx2, PGNs fail to differentiate along the dopaminergic lineage, but rather assume a calretinin + fate (hence the PGN subtype lacking Dlx2 and Pax6). Instead, calretinin + neuron specification requires Sp8 (Waclaw et al., 2006) and in the absence of Sp8 Pax6 is upregulated, suggesting that the balance between Pax6/ Dlx2 and Sp8, respectively, regulates the proportion of PGNs with distinct identities. Conversely, overexpression of either Pax6 or Dlx2 promotes dopaminergic at the expense of calretinin+ PGNs. Cre-mediated deletion of Pax6 did not affect the proportion of calbindin + cells, even though this population also lacks endogenous Pax6. This indicates that the respective increase in calretinin + PGNs is not merely a "passive" consequence of the loss of the dopaminergic phenotype, but rather that Dlx2 and Pax6 actively inhibit calretinin + subtype specification.

These observations also bear relevance in regard to the diverse origin of PGN subtypes at distinct positions and the proposition that distinct stem cell pools are fate-restricted toward the generation of specific neuronal subtypes (Hack et al., 2005; Kelsch et al., 2007; Merkle et al., 2007). Our studies indicate a substantial degree of plasticity: forced expression of either Pax6 or Dlx2 in the RMS can convert progeny toward a TH+ PGN fate at the expense of both calretinin + PGNs and granule cells, indicating that independent of their respective origin, the derivatives of distinct stem cell pools have the competence to interpret the transcriptional cues and adopt different neuronal subtypes. Given that the majority of adult SEZ stem cells are derived from the ganglionic eminences, the fate restriction of their progeny may be acquired already at the embryonic stage and passed onto the adult offspring. Alternatively, adult SEZ stem cells may be exposed to local domains of niche factors such as BMP and Sonic hedgehog (Palma et al., 2005; Colak et al., 2008), thereby creating distinct progenitor domains with different fate restrictions.

Our data highlight the importance of understanding the molecular code specifying neuronal diversity in the adult brain. Obviously, the aim to regenerate specific types of neurons requires a thorough understanding of the molecular mechanisms directing differentiation of the respectively required neuronal subtypes. 
Interestingly, the key players are similar in the developing and adult nervous system, but their functional cooperation seems to be unique to adult neurogenesis. Pax6 and Dlx2 are coexpressed in neurons differentiating along a dopaminergic identity in the developing diencephalon (Mastick and Andrews, 2001; Andrews et al., 2003). However, despite their coexpression, only Dlx1 and Dlx2 (Andrews et al., 2003), not Pax6, are required for these neurons to develop their dopaminergic identity (Mastick and Andrews, 2001). These data suggest that the intimate interaction and mutual requirement between Dlx and Pax6 may be specific to dopaminergic subtype specification in the adult OB. The identification of the cooperation of Pax6 and Dlx2 in dopaminergic PGN specification provides a significant step forward in our understanding of how the acquisition of this transmitter identity is controlled in the adult brain.

\section{References}

Allen II ZJ, Waclaw RR, Colbert MC, Campbell K (2007) Molecular identity of olfactory bulb interneurons: transcriptional codes of periglomerular neuron subtypes. J Mol Histol 38:517-525.

Alvarez-Buylla A, Garcia-Verdugo JM, Tramontin AD (2001) A unified hypothesis on the lineage of neural stem cells. Nat Rev Neurosci 2:287-293.

Anderson SA, Eisenstat DD, Shi L, Rubenstein JL (1997) Interneuron migration from basal forebrain to neocortex: dependence on Dlx genes. Science 278:474-476.

Anderson SA, Kaznowski CE, Horn C, Rubenstein JL, McConnell SK (2002) Distinct origins of neocortical projection neurons and interneurons in vivo. Cereb Cortex 12:702-709.

Andrews GL, Yun K, Rubenstein JL, Mastick GS (2003) Dlx transcription factors regulate differentiation of dopaminergic neurons of the ventral thalamus. Mol Cell Neurosci 23:107-120.

Ashery-Padan R, Marquardt T, Zhou X, Gruss P (2000) Pax6 activity in the lens primordium is required for lens formation and for correct placement of a single retina in the eye. Genes Dev 14:2701-2711.

Brunjes PC (1994) Unilateral naris closure and olfactory system development. Brain Res Brain Res Rev 19:146-160.

Buffo A, Vosko MR, Erturk D, Hamann GF, Jucker M, Rowitch D, Gotz M (2005) Expression pattern of the transcription factor Olig2 in response to brain injuries: implications for neuronal repair. Proc Natl Acad Sci USA 102:18183-18188.

Cobos I, Borello U, Rubenstein JL (2007) Dlx transcription factors promote migration through repression of axon and dendrite growth. Neuron 54:873-888.

Colak D, Mori T, Brill MS, Pfeifer A, Falk S, Deng C, Monteiro R, Mummery C, Sommer L, Gotz M (2008) Adult neurogenesis requires Smad4mediated bone morphogenic protein signaling in stem cells. J Neurosci 28:434-446.

Corbin JG, Nery S, Fishell G (2001) Telencephalic cells take a tangent: nonradial migration in the mammalian forebrain. Nat Neurosci 4 [Suppl]:1177-1182.

Crespo C, Alonso JR, Brinon JG, Weruaga E, Porteros A, Arevalo R, Aijon J (1997) Calcium-binding proteins in the periglomerular region of typical and typical olfactory glomeruli. Brain Res 745:293-302.

De Marchis S, Bovetti S, Carletti B, Hsieh YC, Garzotto D, Peretto P, Fasolo A, Puche AC, Rossi F (2007) Generation of distinct types of periglomerular olfactory bulb interneurons during development and in adult mice: implication for intrinsic properties of the subventricular zone progenitor population. J Neurosci 27:657-664.

de Melo J, Zhou QP, Zhang Q, Zhang S, Fonseca M, Wigle JT, Eisenstat DD (2008) Dlx2 homeobox gene transcriptional regulation of Trkb neurotrophin receptor expression during mouse retinal development. Nucleic Acids Res 36:872-884.

Ding H, Shannon P, Lau N, Wu X, Roncari L, Baldwin RL, Takebayashi H, Nagy A, Gutmann DH, Guha A (2003) Oligodendrogliomas result from the expression of an activated mutant epidermal growth factor receptor in a RAS transgenic mouse astrocytoma model. Cancer Res 63:1106-1113.

Doetsch F, Petreanu L, Caille I, Garcia-Verdugo JM, Alvarez-Buylla A (2002) EGF converts transit-amplifying neurogenic precursors in the adult brain into multipotent stem cells. Neuron 36:1021-1034.

Eisenstat DD, Liu JK, Mione M, Zhong W, Yu G, Anderson SA, Ghattas I,
Puelles L, Rubenstein JL (1999) DLX-1, DLX-2, and DLX-5 expression define distinct stages of basal forebrain differentiation. J Comp Neurol 414:217-237.

Feng J, White B, Tyurina OV, Guner B, Larson T, Lee HY, Karlstrom RO, Kohtz JD (2004) Synergistic and antagonistic roles of the Sonic hedgehog N- and C-terminal lipids. Development 131:4357-4370.

Fernandes M, Gutin G, Alcorn H, McConnell SK, Hebert JM (2007) Mutations in the BMP pathway in mice support the existence of two molecular classes of holoprosencephaly. Development 134:3789-3794.

Gascon E, Vutskits L, Zhang H, Barral-Moran MJ, Kiss PJ, Mas C, Kiss JZ (2005) Sequential activation of p75 and TrkB is involved in dendritic development of subventricular zone-derived neuronal progenitors in vitro. Eur J Neurosci 21:69-80.

Gorski JA, Talley T, Qiu M, Puelles L, Rubenstein JL, Jones KR (2002) Cortical excitatory neurons and glia, but not GABAergic neurons, are produced in the Emx1-expressing lineage. J Neurosci 22:6309-6314.

Hack MA, Sugimori M, Lundberg C, Nakafuku M, Gotz M (2004) Regionalization and fate specification in neurospheres: the role of Olig2 and Pax6. Mol Cell Neurosci 25:664-678.

Hack MA, Saghatelyan A, de Chevigny A, Pfeifer A, Ashery-Padan R, Lledo PM, Gotz M (2005) Neuronal fate determinants of adult olfactory bulb neurogenesis. Nat Neurosci 8:865-872.

Harris SE, Guo D, Harris MA, Krishnaswamy A, Lichtler A (2003) Transcriptional regulation of BMP-2 activated genes in osteoblasts using gene expression microarray analysis: role of Dlx2 and Dlx5 transcription factors. Front Biosci 8:s1249-s1265.

Heins N, Malatesta P, Cecconi F, Nakafuku M, Tucker KL, Hack MA, Chapouton P, Barde YA, Gotz M (2002) Glial cells generate neurons: the role of the transcription factor Pax6. Nat Neurosci 5:308-315.

Johansson CB, Momma S, Clarke DL, Risling M, Lendahl U, Frisén J (1999) Identification of a neural stem cell in the adult mammalian central nervous system. Cell 96:25-34.

Kaji T, Artinger KB (2004) dlx $3 \mathrm{~b}$ and dlx4b function in the development of Rohon-Beard sensory neurons and trigeminal placode in the zebrafish neurula. Dev Biol 276:523-540.

Kelsch W, Mosley CP, Lin CW, Lois C (2007) Distinct mammalian precursors are committed to generate neurons with defined dendritic projection patterns. PLoS Biol 5:e300.

Kohtz RJ, Petterson CM, Mills NJ, Kmiecik SA, Liu JL, Nichols JD, Vaadia TS, Stammers AH (2001) Effects of ultrafiltration on enoxaparin: an in vitro analysis. J Extra Corpor Technol 33:94-99.

Kohwi M, Osumi N, Rubenstein JL, Alvarez-Buylla A (2005) Pax6 is required for making specific subpopulations of granule and periglomerular neurons in the olfactory bulb. J Neurosci 25:6997-7003.

Kohwi M, Petryniak MA, Long JE, Ekker M, Obata K, Yanagawa Y, Rubenstein JL, Alvarez-Buylla A (2007) A subpopulation of olfactory bulb GABAergic interneurons is derived from Emx1- and Dlx5/6-expressing progenitors. J Neurosci 27:6878-6891.

Kosaka K, Aika Y, Toida K, Heizmann CW, Hunziker W, Jacobowitz DM, Nagatsu I, Streit P, Visser TJ, Kosaka T (1995) Chemically defined neuron groups and their subpopulations in the glomerular layer of the rat main olfactory bulb. Neurosci Res 23:73-88.

Kroll TT, O'Leary DD (2005) Ventralized dorsal telencephalic progenitors in Pax6 mutant mice generate GABA interneurons of a lateral ganglionic eminence fate. Proc Natl Acad Sci USA 102:7374-7379.

Le TN, Du G, Fonseca M, Zhou QP, Wigle JT, Eisenstat DD (2007) Dlx homeobox genes promote cortical interneuron migration from the basal forebrain by direct repression of the semaphorin receptor neuropilin- 2 . J Biol Chem 282:19071-19081.

Levi G, Puche AC, Mantero S, Barbieri O, Trombino S, Paleari L, Egeo A, Merlo GR (2003) The Dlx5 homeodomain gene is essential for olfactory development and connectivity in the mouse. Mol Cell Neurosci 22:530-543.

Lo LC, Johnson JE, Wuenschell CW, Saito T, Anderson DJ (1991) Mammalian achaete-scute homolog 1 is transiently expressed by spatially restricted subsets of early neuroepithelial and neural crest cells. Genes Dev 5:1524-1537.

Lu QR, Sun T, Zhu Z, Ma N, Garcia M, Stiles CD, Rowitch DH (2002) Common developmental requirement for Olig function indicates a motor neuron/oligodendrocyte connection. Cell 109:75-86.

Malatesta P, Hack MA, Hartfuss E, Kettenmann H, Klinkert W, Kirchhoff F, 
Gotz M (2003) Neuronal or glial progeny: regional differences in radial glia fate. Neuron 37:751-764.

Marin O, Rubenstein JL (2001) A long, remarkable journey: tangential migration in the telencephalon. Nat Rev Neurosci 2:780-790.

Mastick GS, Andrews GL (2001) Pax6 regulates the identity of embryonic diencephalic neurons. Mol Cell Neurosci 17:190-207.

McTigue DM, Wei P, Stokes BT (2001) Proliferation of NG2-positive cells and altered oligodendrocyte numbers in the contused rat spinal cord. J Neurosci 21:3392-3400.

Mendoza-Torreblanca JG, Martinez-Martinez E, Tapia-Rodriguez M, Ramirez-Hernandez R, Gutierrez-Ospina G (2008) The rostral migratory stream is a neurogenic niche that predominantly engenders periglomerular cells: in vivo evidence in the adult rat brain. Neurosci Res 60:289-299.

Menn B, Garcia-Verdugo JM, Yaschine C, Gonzalez-Perez O, Rowitch D, Alvarez-Buylla A (2006) Origin of oligodendrocytes in the subventricular zone of the adult brain. J Neurosci 26:7907-7918.

Merkle FT, Mirzadeh Z, Alvarez-Buylla A (2007) Mosaic organization of neural stem cells in the adult brain. Science 317:381-384.

Ming GL, Song H (2005) Adult neurogenesis in the mammalian central nervous system. Annu Rev Neurosci 28:223-250.

Miyoshi G, Butt SJ, Takebayashi H, Fishell G (2007) Physiologically distinct temporal cohorts of cortical interneurons arise from telencephalic Olig2expressing precursors. J Neurosci 27:7786-7798.

Mullen RJ, Buck CR, Smith AM (1992) NeuN, a neuronal specific nuclear protein in vertebrates. Development 116:201-211.

Nam SC, Kim Y, Dryanovski D, Walker A, Goings G, Woolfrey K, Kang SS, Chu C, Chenn A, Erdelyi F, Szabo G, Hockberger P, Szele FG (2007) Dynamic features of postnatal subventricular zone cell motility: a twophoton time-lapse study. J Comp Neurol 505:190-208.

Nikoletopoulou V, Plachta N, Allen ND, Pinto L, Gotz M, Barde YA (2007) Neurotrophin receptor-mediated death of misspecified neurons generated from embryonic stem cells lacking Pax6. Cell Stem Cell 1:529-540.

Nosaka T, Kawashima T, Misawa K, Ikuta K, Mui AL, Kitamura T (1999) STAT5 as a molecular regulator of proliferation, differentiation and apoptosis in hematopoietic cells. EMBO J 18:4754-4765.

Palma V, Lim DA, Dahmane N, Sanchez P, Brionne TC, Herzberg CD, Gitton Y, Carleton A, Alvarez-Buylla A, Ruiz i Altaba A (2005) Sonic hedgehog controls stem cell behavior in the postnatal and adult brain. Development 132:335-344.

Panganiban G, Sebring A, Nagy L, Carroll S (1995) The development of crustacean limbs and the evolution of arthropods. Science 270:1363-1366.

Panzanelli P, Fritschy JM, Yanagawa Y, Obata K, Sassoé-Pognetto M (2007) GABAergic phenotype of periglomerular cells in the rodent olfactory bulb. J Comp Neurol 502:990-1002.

Parras CM, Galli R, Britz O, Soares S, Galichet C, Battiste J, Johnson JE, Nakafuku M, Vescovi A, Guillemot F (2004) Mash1 specifies neurons and oligodendrocytes in the postnatal brain. EMBO J 23:4495-4505.
Parrish-Aungst S, Shipley MT, Erdelyi F, Szabo G, Puche AC (2007) Quantitative analysis of neuronal diversity in the mouse olfactory bulb. J Comp Neurol 501:825-836.

Pear WS, Nolan GP, Scott ML, Baltimore D (1993) Production of high-titer helper-free retroviruses by transient transfection. Proc Natl Acad Sci USA 90:8392-8396.

Petryniak MA, Potter GB, Rowitch DH, Rubenstein JL (2007) Dlx1 and Dlx2 control neuronal versus oligodendroglial cell fate acquisition in the developing forebrain. Neuron 55:417-433.

Qiu M, Bulfone A, Martinez S, Meneses JJ, Shimamura K, Pedersen RA, Rubenstein JL (1995) Null mutation of Dlx-2 results in abnormal morphogenesis of proximal first and second branchial arch derivatives and abnormal differentiation in the forebrain. Genes Dev 9:2523-2538.

Rowitch DH (2004) Glial specification in the vertebrate neural tube. Nat Rev Neurosci 5:409-419.

Shimogori T, Banuchi V, Ng HY, Strauss JB, Grove EA (2004) Embryonic signaling centers expressing BMP, WNT and FGF proteins interact to pattern the cerebral cortex. Development 131:5639-5647.

Stoykova A, Fritsch R, Walther C, Gruss P (1996) Forebrain patterning defects in Small eye mutant mice. Development 122:3453-3465.

Toresson H, Campbell K (2001) A role for Gsh1 in the developing striatum and olfactory bulb of Gsh2 mutant mice. Development 128:4769-4780.

Toresson H, Potter SS, Campbell K (2000) Genetic control of dorsal-ventral identity in the telencephalon: opposing roles for Pax6 and Gsh2. Development 127:4361-4371.

Ventura RE, Goldman JE (2007) Dorsal radial glia generate olfactory bulb interneurons in the postnatal murine brain. J Neurosci 27:4297-4302.

Waclaw RR, Allen II ZJ, Bell SM, Erdelyi F, Szabo G, Potter SS, Campbell K (2006) The zinc finger transcription factor Sp8 regulates the generation and diversity of olfactory bulb interneurons. Neuron 49:503-516.

Willaime-Morawek S, Seaberg RM, Batista C, Labbe E, Attisano L, Gorski JA, Jones KR, Kam A, Morshead CM, van der Kooy D (2006) Embryonic cortical neural stem cells migrate ventrally and persist as postnatal striatal stem cells. J Cell Biol 175:159-168.

Wilson SW, Rubenstein JL (2000) Induction and dorsoventral patterning of the telencephalon. Neuron 28:641-651.

Winner B, Cooper-Kuhn CM, Aigner R, Winkler J, Kuhn HG (2002) Longterm survival and cell death of newly generated neurons in the adult rat olfactory bulb. Eur J Neurosci 16:1681-1689.

Woda JM, Pastagia J, Mercola M, Artinger KB (2003) Dlx proteins position the neural plate border and determine adjacent cell fates. Development 130:331-342.

Yee JK, Friedmann T, Burns JC (1994) Generation of high-titer pseudotyped retroviral vectors with very broad host range. Methods Cell Biol 43:99-112.

Young KM, Fogarty M, Kessaris N, Richardson WD (2007) Subventricular zone stem cells are heterogeneous with respect to their embryonic origins and neurogenic fates in the adult olfactory bulb. J Neurosci 27:82868296. 